\title{
Aerosol indirect effects in a multi-scale aerosol-climate model PNNL-MMF
}

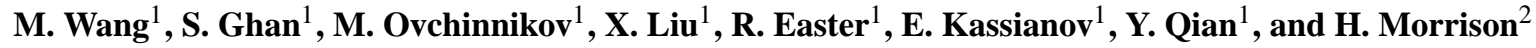 \\ ${ }^{1}$ Atmospheric Science and Global Change Division, Pacific Northwest National Laboratory, Richland, Washington, USA \\ ${ }^{2}$ Mesoscale and Microscale Meteorology Division, National Center for Atmospheric Research, Boulder, Colorado, USA
}

Received: 14 January 2011 - Published in Atmos. Chem. Phys. Discuss.: 31 January 2011

Revised: 30 May 2011 - Accepted: 30 May 2011 - Published: 9 June 2011

\begin{abstract}
Much of the large uncertainty in estimates of anthropogenic aerosol effects on climate arises from the multiscale nature of the interactions between aerosols, clouds and dynamics, which are difficult to represent in conventional general circulation models (GCMs). In this study, we use a multi-scale aerosol-climate model that treats aerosols and clouds across multiple scales to study aerosol indirect effects. This multi-scale aerosol-climate model is an extension of a multi-scale modeling framework (MMF) model that embeds a cloud-resolving model (CRM) within each vertical column of a GCM grid. The extension allows a more physicallybased treatment of aerosol-cloud interactions in both stratiform and convective clouds on the global scale in a computationally feasible way. Simulated model fields, including liquid water path (LWP), ice water path, cloud fraction, shortwave and longwave cloud forcing, precipitation, water vapor, and cloud droplet number concentration are in reasonable agreement with observations. The new model performs quantitatively similar to the previous version of the MMF model in terms of simulated cloud fraction and precipitation. The simulated change in shortwave cloud forcing from anthropogenic aerosols is $-0.77 \mathrm{~W} \mathrm{~m}^{-2}$, which is less than half of that $\left(-1.79 \mathrm{~W} \mathrm{~m}^{-2}\right)$ calculated by the host GCM (NCAR CAM5) with traditional cloud parameterizations and is also at the low end of the estimates of other conventional global aerosol-climate models. The smaller forcing in the MMF model is attributed to a smaller (3.9\%) increase in LWP from preindustrial conditions (PI) to present day (PD) compared with $15.6 \%$ increase in LWP in stratiform clouds in CAM5. The difference is caused by a much smaller response in LWP to a given perturbation in cloud condensation nuclei (CCN) concentrations from PI to PD in the MMF (about one-third of that in CAM5), and, to a lesser
\end{abstract}

Correspondence to: $\mathrm{M}$. Wang (minghuai.wang@pnnl.gov) extent, by a smaller relative increase in $\mathrm{CCN}$ concentrations from PI to PD in the MMF (about 26\% smaller than that in CAM5). The smaller relative increase in $\mathrm{CCN}$ concentrations in the MMF is caused in part by a smaller increase in aerosol lifetime from PI to PD in the MMF, a positive feedback in aerosol indirect effects induced by cloud lifetime effects from aerosols. The smaller response in LWP to anthropogenic aerosols in the MMF model is consistent with observations and with high resolution model studies, which may indicate that aerosol indirect effects simulated in conventional global climate models are overestimated and point to the need to use global high resolution models, such as MMF models or global CRMs, to study aerosol indirect effects. The simulated total anthropogenic aerosol effect in the MMF is $-1.05 \mathrm{~W} \mathrm{~m}^{-2}$, which is close to the Murphy et al. (2009) inverse estimate of $-1.1 \pm 0.4 \mathrm{~W} \mathrm{~m}^{-2}(1 \sigma)$ based on the examination of the Earth's energy balance. Further improvements in the representation of ice nucleation and low clouds in MMF are needed to refine the aerosol indirect effect estimate.

\section{Introduction}

Clouds are an extremely important climate regulator. They have a large impact on the Earth's energy budget and play a central role in the hydrological cycle. By acting as cloud condensation nuclei (CCN) or ice nuclei (IN), anthropogenic aerosols can modify cloud optical and physical properties, and therefore affect the climate system, giving rise to the so-called aerosol indirect effect. Uncertainties in estimates of the anthropogenic aerosol indirect effect still dominate uncertainties in the estimates of radiative forcing of past and future climate change, despite more than a decade of effort on this issue (Forster et al., 2007; IPCC, 2007; Lohmann et al., 2010). 
Much of this uncertainty arises from the multi-scale nature of the interactions between aerosols, clouds, and dynamics (e.g., Rosenfeld et al., 2006; Wood et al., 2011). These interactions span a wide range in spatial scales, from 0.01$10 \mu \mathrm{m}$ for droplet and crystal nucleation, to $10-1000 \mathrm{~m}$ for turbulence-driven updrafts, to $2-10 \mathrm{~km}$ for deep convection, to $50-100 \mathrm{~km}$ for large-scale cloud systems. Given the typical general circulation model (GCM) grid spacing of a hundred kilometers, the treatment of most of those processes is highly parameterized in conventional GCMs and therefore may not be accurate.

One example is cloud lifetime effects from aerosols. In most GCMs, it is assumed that, because of less efficient coalescence and collection among cloud droplets, increasing cloud droplet number concentrations from anthropogenic aerosols always slow formation of precipitation and increases liquid water path (LWP) and cloud lifetime (Albrecht, 1989). However, observations show evidence of both decreasing and increasing LWP with increasing aerosols (Platnick et al., 2000; Coakley and Walsh, 2002; Kaufman et al., 2005; Matsui et al., 2006), and cloud resolving model (CRM) studies show that changes in LWP depend on meteorological conditions (Ackerman et al., 2004; Xue et al., 2008; Small et al., 2009).

It is even more problematic to represent aerosol/cloud processes in deep cumulus clouds in GCMs. Cumulus parameterizations in current climate models rely on ad hoc closure assumptions designed to diagnose the latent heating and vertical transport of heat and moisture by deep convection, and provide little information about microphysics or updraft velocity (Emanuel and Zivkovic-Rothman, 1999; Del Genio et al., 2005; Zhang et al., 2005). As a result, only a handful of GCMs have treated aerosol effects on convective clouds in their estimates of aerosol indirect effects (Menon and Rotstayn, 2006; Lohmann, 2008), and because those treatments were based on conventional cumulus parameterizations, the treatments are quite crude. Menon and Rotstayn (2006) introduced a physically-based treatment of aerosol effects on convective cloud microphysics in two GCMs and found a strong dependence of indirect effects on the details of the cumulus parameterization: including aerosol effects on convective clouds increased aerosol indirect effects in one GCM but slightly decreased aerosol indirect effects in the other GCM. Lohmann (2008) investigated aerosol effects on convective clouds by extending a double-moment cloud microphysics scheme developed for stratiform clouds to convective clouds, and found that including aerosol effects in convective clouds reduces the sensitivity of the LWP to aerosol optical depth (AOD), which is in better agreement with observations and large-eddy simulation studies and leads to slightly smaller total aerosol forcing. Clearly, more physically-based modeling studies are needed to better quantify the response of all cloud types to changes in aerosol loading and to narrow down the aerosol indirect effect estimates.
We have recently developed a new aerosol-climate model (Wang et al., 2011), which is an extension of a multi-scale modeling framework (MMF) model that embeds a CRM within each grid column of a GCM (Khairoutdinov et al., 2008). The GCM component includes a modal aerosol treatment that uses several log-normal modes to represent aerosol size distributions. The CRM component has a two-moment microphysics scheme and predicts both mass and number mixing ratios for all hydrometeor types. Cloud statistics diagnosed from the CRM component are used to drive the aerosol and trace gas processing by clouds. This multi-scale aerosol-climate model, hereafter called PNNL-MMF, allows us to simulate aerosol-cloud interactions in both stratiform and convective clouds in a more physically-based manner. Compared to global CRMs with on-line aerosols (Suzuki et al., 2008), this multi-scale aerosol-climate model is computationally much more feasible for running multi-year climate simulations. Wang et al. (2011) showed that the model simulates aerosol fields as well as conventional aerosol-climate models.

In this study, we evaluate simulated cloud fields from this multi-scale aerosol-climate model, and examine anthropogenic aerosol effects on clouds and climate. Section 2 describes the model. Model results with the present day aerosol and precursor emissions are shown in Sect. 3. The aerosol indirect effects are examined in Sect. 4 and finally the results are summarized in Sect. 5.

\section{Model description and set-up of simulations}

\subsection{Model description}

The PNNL-MMF is documented in detail in Wang et al. (2011) and is only briefly described here. It is an extension of the Colorado State University (CSU) MMF model (Randall et al., 2003; Khairoutdinov et al., 2005, 2008; Tao et al., 2009), first developed by Khairoutdinov and Randall (2001). The host GCM in the PNNL-MMF is upgraded to the latest version of the Community Atmospheric Model (CAM5) (http://www.cesm.ucar.edu/models/cesm1.0/cam/), which is the atmospheric component of the Community Earth System Model (CESM1.0). The embedded CRM in each GCM grid column is a two-dimensional version of the System for Atmospheric Modeling (SAM) (Khairoutdinov and Randall, 2003), which replaces the conventional moist physics, convective cloud, turbulence, and boundary layer parameterizations in CAM5. During each GCM time step (every $10 \mathrm{~min}$ ), the CRM is forced by the large-scale temperature and moisture tendencies arising from GCM-scale dynamical processes and feeds the cloud response back to the GCMscale as heating and moistening terms in the large-scale budget equations for heat and moisture. The CRM runs continuously using a 20 -s time step. 
The version of the SAM CRM used in this study features a two-moment cloud microphysics scheme (Morrison et al., 2005, 2009), which replaces the simple bulk microphysics used in the original CSU MMF model. The new scheme predicts the number concentrations and mass mixing ratios of five hydrometeor types (cloud droplets, ice crystals, rain droplets, snow particles, and graupel particles). The precipitation hydrometeor types (rain, snow, and graupel) are fully prognostic in the CRM model, rather than diagnostic as in CAM5 (Morrison and Gettelman, 2008). Droplet activation from hydrophilic aerosols, ice nucleation, ice crystal growth by vapor deposition, the dependence of ice crystal sedimentation on crystal number, and the dependence of autoconversion on droplet number are treated. Several ice nucleation mechanisms are included: contact nucleation of cloud droplets following Morrison and Pinto (2005); immersion freezing of cloud droplets and rain following Bigg (1953); deposition-condensation freezing nucleation following Thompson et al. (2004), which is based on ice crystal concentration measurements of Cooper (1986) and limited to a maximum of $0.5 \mathrm{~cm}^{-3}$; and homogeneous freezing of all cloud and rain drops below $-40^{\circ} \mathrm{C}$. These ice nucleation treatments do not directly link heterogeneous IN to aerosols. Droplet activation is calculated at each CRM grid cell, based on the parameterization of Abdul-Razzak and Ghan (2000). The vertical velocity for calculating droplet activation is the sum of the resolved vertical velocity and a sub-grid vertical velocity that is diagnosed from the turbulence kinetic energy (Wang et al, 2011). A minimum vertical velocity of $0.1 \mathrm{~m} \mathrm{~s}^{-1}$ is set, following Ghan et al. (1997). Short-term sensitivity tests show that including sub-grid vertical velocity is critical to simulate reasonable cloud droplet number concentrations compared with observations, while the choice of the minimum vertical velocity is less critical. Aerosol fields used in droplet activation in the CRM are predicted on the GCM grid cells as described next.

CAM5, the driving GCM, uses a modal approach to treat aerosols (Liu et al., 2011). Aerosol size distributions are represented by three log-normal modes: an Aitken mode, an accumulation mode, and a single coarse mode. Aitken mode species include sulfate, secondary organic aerosol (SOA), and sea salt; accumulation mode species include sulfate, SOA, black carbon (BC), primary organic matter (POM), sea salt, and dust; coarse mode species include sea salt, dust, and sulfate. Species mass mixing ratios within each mode are predicted as well as number mixing ratio for that mode, while mode widths are prescribed. Aerosols outside cloud droplets (interstitial aerosols) and aerosols within cloud droplets (cloud-borne aerosols) are both predicted. Aerosol nucleation (involving $\mathrm{H}_{2} \mathrm{SO}_{4}$ vapor), condensation of trace gases $\left(\mathrm{H}_{2} \mathrm{SO}_{4}\right.$ and semi-volatile organics) on existing aerosol particles, and coagulation (Aitken and accumulation modes) are also treated.

In the PNNL-MMF, the treatment of cloud-related aerosol and trace gas processes (i.e., aqueous chemistry, convective transport, and wet scavenging) in the standard CAM5 is replaced by the explicit-cloud-parameterized-pollutant (ECPP) approach (Gustafson et al., 2008; Wang et al., 2011). The ECPP approach uses statistics of cloud distribution, vertical velocity, and cloud microphysical properties resolved by the CRM to drive aerosol and chemical processing by clouds on the GCM grid, which allows us to treat the effects of convective clouds on aerosols in a more physicallybased and computationally feasible manner. The ECPP approach predicts both interstitial aerosols and cloud-borne aerosols in all clouds, while the conventional CAM5 only treats cloud-borne aerosols in stratiform clouds. In addition, by integrating the continuity equation for aerosols and trace gases in convective updraft and downdraft regions, the ECPP approach treats convective transport, aqueous chemistry, and wet scavenging in an integrated and self-consistent way (Wang et al., 2011).

The CAM5 radiative transfer scheme uses the Rapid Radiative Transfer Model for GCMs (RRTMG), a broadband $\mathrm{k}$-distribution radiation model developed for application to GCMs (Mlawer et al., 1997; Iacono et al., 2003, 2008). The CAM5 radiative transfer calculation is applied to each CRM column at each GCM time step (10 min), assuming 1 or 0 cloud fraction at each CRM grid cell. Aerosol optical properties are diagnosed on the CRM grid using the dry aerosol properties on the GCM grid and calculating aerosol water uptake from Kohler theory based on the relative humidity on the CRM grid, accounting for hysteresis and the hygroscopicities of each of the modes' components (Ghan and Zaveri, 2007).

\subsection{Emissions and set-up of simulations}

The host GCM (CAM5) uses a finite-volume dynamical core, with 30 vertical levels at $1.9^{\circ} \times 2.5^{\circ}$ horizontal resolution. The GCM time step is 10 minutes. Climatological sea surface temperature and sea ice are prescribed. The embedded CRM includes 32 columns at 4-km horizontal grid spacing and 28 vertical layers coinciding with the lowest 28 CAM levels. The time step for the embedded CRM is $20 \mathrm{~s}$. The MMF model was integrated for 36 months, and results from the last 34 months are used in this study. Results from the MMF model are also compared with those from the conventional CAM5. The conventional CAM5 runs at $1.9^{\circ} \times 2.5^{\circ}$ horizontal resolution with 30 vertical levels and a time step of $30 \mathrm{~min}$, and was integrated for $5 \mathrm{yr}$. Results from the last four years are reported here. The three-mode aerosol scheme and the modified Morrison-Gettelman two-moment cloud scheme are used for large-scale processes in CAM5 (Gettelman et al., 2010), and shallow and deep convective clouds are parameterized with no explicit aerosol effects.

Both the MMF and CAM5 use the same aerosol and precursor emissions as described in Liu et al. (2011) and Wang et al. (2011). Anthropogenic $\mathrm{SO}_{2}, \mathrm{BC}$, and POM emissions are from the Lamarque et al. (2010) IPCC AR5 emission data set. The years 2000 and 1850 are chosen to represent the 
present day (PD) and the pre-industrial (PI) time, respectively. Volcanic $\mathrm{SO}_{2}$ and DMS emissions are taken from Dentener et al. (2006), and $2.5 \%$ of $\mathrm{SO}_{2}$ emissions are emitted as primary sulfate aerosol. Aerosol number emissions are derived from mass emissions using species densities and volume mean emission diameters, which vary with species and emission sector. In the simplified SOA mechanism in CAM5 (Liu et al., 2011), condensing gas-phase organic species, which condense (reversibly) to give SOA, are emitted directly in the model using prescribed yields for several primary volatile organic compound (VOC) classes, rather than being formed by atmospheric oxidation. The VOC emissions are taken from the MOZART-2 data set (Horowitz et al., 2003). Emissions of sea salt and mineral dust aerosols are calculated online. The sea salt emission parameterization follows Martensson et al. (2003) and particles with diameters between $0.02-0.08,0.08-1.0$, and $1.0-10.0 \mu \mathrm{m}$ are placed in the Aitken, accumulation, and coarse modes, respectively. Mineral dust emissions are calculated with the Dust Entrainment and Deposition Model (Zender et al., 2003); the implementation in CAM has been described in Mahowald et al. (2006a, b) and Yoshioka et al. (2007). Dust particles with diameters between $0.1-1.0$ and $1.0-10.0 \mu \mathrm{m}$ are placed in the accumulation and coarse modes, respectively.

Two simulations are performed for both the MMF and CAM5: one with the PD aerosol and precursor emissions, and the other with the PI aerosol and precursor emissions. Greenhouse gases are fixed at the present day level in all simulations.

\section{Model results in the PD simulations}

\subsection{Cloud fields}

\subsubsection{Global and annual averages}

Table 1 lists global annual means of simulated cloud and radiation parameters in the MMF, along with those from the conventional CAM5 and observations. The liquid water path (LWP) in the MMF simulation is $55.9 \mathrm{~g} \mathrm{~m}^{-2}$, which is slightly larger than the total LWP (stratiform + convective clouds) simulated by CAM5 $\left(48.4 \mathrm{~g} \mathrm{~m}^{-2}\right)$ and is in the observed range of $50-84 \mathrm{~g} \mathrm{~m}^{-2}$. Cloud-top droplet number concentration for low level (cloud-top pressure higher than $640 \mathrm{hPa}$ ), and warm (cloud-top temperature warmer than $273.16 \mathrm{~K}$ ) clouds in the MMF is $109 \mathrm{~cm}^{-3}$, which is slightly lower than that in CAM5 $\left(121 \mathrm{~cm}^{-3}\right)$. Cloud-top droplet effective radius for low level and warm clouds in the MMF is $9.2 \mu \mathrm{m}$, which is slightly larger than that in CAM5 $(9.0 \mu \mathrm{m})$, with both values being below those retrieved from satellites $(11.4-15.7 \mu \mathrm{m})$. Simulated columnintegrated grid-mean cloud droplet number concentration $\left(2.3 \times 10^{10} \mathrm{~m}^{-2}\right)$ in the MMF is nearly $50 \%$ higher than that in CAM5 $\left(1.6 \times 10^{10} \mathrm{~m}^{-2}\right)$. The large difference in column- integrated cloud droplet number concentrations between the MMF and CAM5 can be partly explained by the fact that column-integrated cloud droplet number concentration in CAM5 only includes contributions from stratiform clouds while the MMF value includes contributions from both stratiform and convective clouds. Convective clouds tend to have larger vertical velocities, which result in higher maximum supersaturation and activation of a larger fraction of $\mathrm{CCN}$, thereby producing more numerous cloud droplets.

Simulated cloud ice water path, snow water path, and graupel water path are $9.9,53.4$, and $5.7 \mathrm{~g} \mathrm{~m}^{-2}$, respectively. The total frozen water path is $69.0 \mathrm{~g} \mathrm{~m}^{-2}$ and is close to that simulated in CAM5 $\left(61.3 \mathrm{~g} \mathrm{~m}^{-2}\right.$ from the sum of snow and ice water path). It is also close to that retrieved from CloudSat (75 $\pm 30 \mathrm{~g} \mathrm{~m}^{-2}$, from Austin et al., 2009), and MODIS $\left(60 \mathrm{~g} \mathrm{~m}^{-2}\right)$, but is much larger than estimates from ISCCP (around $35 \mathrm{~g} \mathrm{~m}^{-2}$ ) and NOAA NESDIS (around $10 \mathrm{~g} \mathrm{~m}^{-2}$ ) (IWP from MODIS, ISCCP, and NESDIS can be found in Fig. 18 in Waliser et al., 2009). CloudSat retrievals are sensitive to large hydrometeor particles and are considered to be more representative of total frozen water (Austin et al., 2009; Waliser et al., 2009). The partitioning of total frozen water among different ice hydrometeor components in PNNLMMF is similar to that in the NASA fvMMF model (Waliser et al., 2009), which is another MMF model treating multiple hydrometeor types (Tao et al., 2009). Both the PNNLMMF and NASA fvMMF simulate a small contribution from cloud ice water over the tropics $\left(30^{\circ} \mathrm{S}-30^{\circ} \mathrm{N}\right)(13 \%$ in the PNNL MMF, compared with $10 \%$ in the NASA fvMMF). However, the PNNL MMF produces a much smaller contribution from graupel (14\%), compared with that in the NASA fvMMF $(50 \%)$. These differences may result from the differences in the microphysics schemes in the CRM components in the two MMF models. For example, the CRM component in the NASA fvMMF employs a single-moment bulk microphysics scheme (Tao et al., 2003), while the two-moment microphysics scheme is used in the PNNL MMF (Sect. 2.1). Though the density of snow and graupel are the same in both MMFs (snow: $0.1 \mathrm{~g} \mathrm{~m}^{-3}$; graupel: $0.4 \mathrm{~g} \mathrm{~m}^{-3}$ ), the density of cloud ice is smaller in the PNNL MMF $\left(0.5 \mathrm{~g} \mathrm{~m}^{-3}\right.$ vs. $0.92 \mathrm{~g} \mathrm{~m}^{-3}$ in the NASA fvMMF). Given the fact that no global observation is able to distinguish different ice hydrometeors, it is still difficult to constrain the partitioning among different hydrometeors in GCMs.

Simulated column-integrated ice crystal number concentration is $0.021 \times 10^{10} \mathrm{~m}^{-2}$, which is twice that in CAM5. The ice nucleation treatment in the MMF model does not directly link heterogeneous IN to aerosols although aerosols can influence the ice crystal number concentration through freezing of cloud droplets activated on aerosols. In CAM5, sulfate can form ice crystals in cirrus clouds through homogeneous freezing, and dust can act as heterogeneous IN in cirrus and mixed-phase clouds (Gettelman et al., 2010). Large uncertainties exist in simulated column-integrated ice crystal number concentrations in global climate models 
Table 1. Annual global mean cloud and radiation parameters from MMF and CAM5 simulations (PD and PI) and observations: total cloud fraction (CLDTOT), low cloud fraction (CLDLOW), high cloud fraction (CLDHGH), shortwave cloud forcing (SWCF), longwave cloud forcing (LWCF), column-integrated grid-mean hydrometeor water path (LWP, liquid water path; RWP, rain water path; IWP, ice water path; SWP, snow water path; GWP, graupel water path; TIWP, total ice water path, and TIWP=IWP+SWP+GWP), column-integrated grid-mean hydrometeor number concentrations ( $N_{d}$, cloud droplets; $N_{i}$, ice crystals; $N_{r}$, rain droplets; $N_{s}$, snow crystals; $N_{g}$, graupel particles), cloudtop droplet number concentrations (CDNC) and droplet effective radius at cloud top (CDR) for low level warm clouds, precipitation rate (Precip), column-integrated water vapor (Wmv), AOD, whole-sky shortwave (FSNT) and longwave (FLNT) net radiative fluxes at the top of the atmosphere, clear-sky shortwave (FSNTC) and longwave (FLNTC) radiative fluxes at the top of the atmosphere.

\begin{tabular}{|c|c|c|c|c|c|}
\hline & $\begin{array}{r}\text { MMF } \\
\text { (PD) }\end{array}$ & $\begin{array}{r}\mathrm{MMF} \\
(\mathrm{PI})\end{array}$ & $\begin{array}{r}\text { CAM5 } \\
\text { (PD) }\end{array}$ & $\begin{array}{r}\text { CAM5 } \\
\text { (PI) }\end{array}$ & Obs \\
\hline CLDTOT (-) & $55.79 \%$ & $55.75 \%$ & $62.66 \%$ & $62.49 \%$ & $65-75^{\mathrm{a}}$ \\
\hline CLDLOW (-) & $36.66 \%$ & $36.63 \%$ & $41.47 \%$ & $41.11 \%$ & - \\
\hline CLDHGH (-) & $29.17 \%$ & $29.20 \%$ & $37.61 \%$ & $37.40 \%$ & $21-33^{b}$ \\
\hline $\operatorname{SWCF}\left(\mathrm{W} \mathrm{m}^{-2}\right)$ & -50.49 & -49.72 & -50.12 & -48.33 & -46 to $-53^{c}$ \\
\hline $\operatorname{LWCF}\left(\mathrm{W} \mathrm{m}^{-2}\right)$ & 25.96 & 26.02 & 21.88 & 21.51 & $27-31^{\mathrm{c}}$ \\
\hline $\operatorname{LWP}\left(\mathrm{g} \mathrm{m}^{-2}\right)$ & 55.88 & 53.77 & $\begin{array}{r}48.38 \\
(29.95)^{d}\end{array}$ & $\begin{array}{r}44.45 \\
(25.91)^{d}\end{array}$ & $50-87^{e}$ \\
\hline $\operatorname{RWP}\left(\mathrm{g} \mathrm{m}^{-2}\right)$ & 30.90 & 32.48 & 16.14 & 16.18 & - \\
\hline IWP $\left(\mathrm{g} \mathrm{m}^{-2}\right)$ & 9.91 & 9.91 & $\begin{array}{r}16.08 \\
(7.84)^{d}\end{array}$ & $\begin{array}{r}16.14 \\
(7.72)^{d}\end{array}$ & - \\
\hline $\operatorname{SWP}\left(\mathrm{g} \mathrm{m}^{-2}\right)$ & 53.44 & 53.65 & 45.20 & 45.20 & - \\
\hline $\operatorname{GWP}\left(\mathrm{g} \mathrm{m}^{-2}\right)$ & 5.69 & 5.47 & - & - & - \\
\hline TIWP $\left(\mathrm{g} \mathrm{m}^{-2}\right)$ & 69.04 & 69.03 & 61.28 & 61.34 & $\begin{array}{r}10-65^{f} \\
75 \pm 30^{g}\end{array}$ \\
\hline$N_{d}\left(10^{10} \mathrm{~m}^{-2}\right)$ & 2.28 & 1.80 & 1.53 & 1.09 & - \\
\hline$N_{i}\left(10^{10} \mathrm{~m}^{-2}\right)$ & 0.0212 & 0.0214 & 0.010 & 0.0096 & - \\
\hline$N_{r}\left(10^{10} \mathrm{~m}^{-2}\right)$ & $1.05 \times 10^{-3}$ & $1.29 \times 10^{-3}$ & $9.96 \times 10^{-4}$ & $1.08 \times 10^{-3}$ & - \\
\hline$N_{s}\left(10^{10} \mathrm{~m}^{-2}\right)$ & $1.30 \times 10^{-3}$ & $1.30 \times 10^{-3}$ & $1.64 \times 10^{-3}$ & $1.62 \times 10^{-3}$ & - \\
\hline$N_{g}\left(10^{10} \mathrm{~m}^{-2}\right)$ & $6.35 \times 10^{-6}$ & $6.37 \times 10^{-6}$ & - & - & - \\
\hline $\operatorname{CDNC}\left(\mathrm{cm}^{-3}\right)$ & 109.33 & 84.97 & 120.64 & 91.00 & - \\
\hline $\mathrm{CDR}(\mu \mathrm{m})$ & 9.17 & 9.69 & 8.96 & 9.41 & $11.4-15.7^{\mathrm{h}}$ \\
\hline $\operatorname{Precip}\left(m m\right.$ day $\left.^{-1}\right)$ & 2.85 & 2.86 & 2.95 & 2.97 & $2.61^{\mathrm{i}}$ \\
\hline $\mathrm{Wmv}\left(\mathrm{kg} \mathrm{m}^{-2}\right)$ & 25.47 & 25.46 & 25.87 & 25.75 & $24.6^{\mathrm{j}}$ \\
\hline $\mathrm{AOD}(-)$ & 0.139 & 0.115 & 0.136 & 0.117 & $0.15^{\mathrm{k}}$ \\
\hline $\mathrm{FSNT}^{l}\left(\mathrm{~W} \mathrm{~m}^{-2}\right)$ & 235.36 & 236.67 & 237.28 & 239.53 & $234-242^{\mathrm{c}}$ \\
\hline $\mathrm{FLNT}^{l}\left(\mathrm{~W} \mathrm{~m}^{-2}\right)$ & -232.91 & -233.17 & -235.10 & -235.69 & $-(234-240)^{\mathrm{c}}$ \\
\hline $\operatorname{FSNTC}^{l}\left(\mathrm{~W} \mathrm{~m}^{-2}\right)$ & 285.88 & 286.42 & 287.42 & 287.87 & $287-288^{c}$ \\
\hline $\operatorname{FLNTC}^{1}\left(\mathrm{~W} \mathrm{~m}^{-2}\right)$ & -258.87 & -259.18 & -256.98 & -257.20 & $-(265-269)^{\mathrm{c}}$ \\
\hline
\end{tabular}

\footnotetext{
a Total cloud fraction observations are obtained from ISCCP for the years 1983-2001 (Rossow and Schiffer, 1999), MODIS data for the years 2001-2004 (Platnick, 2003) and HIRS data for the years 1979-2001 (Wylie et al., 2005).

${ }^{\mathrm{b}}$ High cloud fraction observations are obtained from ISCCP data for the years 1983-2001 and HIRS for the years 1979-2001.

c SWCF, LWCF, FSNT, FSNTC, FLNT, and FLNTC are taken from ERBE for the years 1985-1989 (Kiehl and Trenberth, 1997) and CERES for the years 2000-2005 as listed in Table 4 of Loeb et al. (2009).

${ }^{\mathrm{d}}$ Numbers in parenthesis are from large-scale clouds.

e Liquid water path is derived from SSM/I (for the years 1987-1994, Ferraro et al., 1996; for August 1993 and January 1994, Weng and Grody, 1994; and for August 1987 and February 1988, Greenwald et al., 1993) and ISCCP for the year 1987 (Han et al., 1994). SSM/I data are restricted to oceans.

${ }^{\mathrm{f}}$ Total ice water path from NOAA NESDIS, ISCCP, MODIS (Fig. 18 in Waliser et al., 2009).

$\mathrm{g}$ Total ice water path from CloudSat (Austin et al., 2009).

${ }^{\mathrm{h}}$ Cloud-top droplet effective radius is obtained from ISCCP for the year 1987 (Han et al, 1994) and from MODIS (version 4) for the year 2001 (Platnick et al., 2003).

${ }^{\mathrm{i}}$ Precipitation rate is taken from the Global Precipitation Climatology Project (GPCP) for the years 1979-2003 (Adler et al., 2003) (http://www.gewex.org/gpcpdata).

j Precipitable water is from the NASA Water Vapor Project (NVAP) for the years 1988-1999 (Randel et al., 1996). (http://eosweb.larc.nasa.gov/PRODOCS/nvap/table_nvap.html).

${ }^{\mathrm{k}}$ AOD is from a satellite retrieval composite (Kinne et al., 2006).

${ }^{1}$ Positive values mean incoming, while negative values mean outgoing.
} 
(ranges $0.1-0.7 \times 10^{10} \mathrm{~m}^{-2}$ in Lohmann et al. (2008); 0.02$0.09 \times 10^{10} \mathrm{~m}^{-2}$ in Wang and Penner, 2010). Including heterogeneous nucleation in cirrus clouds generally leads to lower ice crystal number concentrations, in better agreement with observed ice crystal number concentrations in the upper troposphere (Wang and Penner, 2010). Aerosol effects on ice nucleation in the MMF will be the subject of a future study.

The total cloud fraction and low cloud fraction in the MMF are $55.8 \%$ and $36.7 \%$, respectively, which are smaller than those in CAM5 $(62.7 \%$ for the total cloud fraction and $41.5 \%$ for the low cloud fraction), though the LWP in the MMF is larger than that in CAM5 $\left(55.9 \mathrm{~g} \mathrm{~m}^{-2}\right.$ vs. $48.4 \mathrm{~g} \mathrm{~m}^{-2}$ ). This suggests that liquid clouds are generally thicker in the MMF than in CAM5. The reason why the MMF generates thicker liquid clouds is not clear, given the large difference in cloud treatments between the MMF and CAM5 (e.g., convective clouds and stratiform clouds are parameterized separately and no direct relationship between LWC and cloud fraction in CAM5, while both stratiform and convective clouds are explicitly simulated using the embedded CRM in the MMF). The total cloud fraction in the MMF is smaller than that in observations $(65-75 \%)$. Simulated high cloud fraction, $29.2 \%$, is smaller than that in CAM5.

Shortwave cloud forcing is $-50.5 \mathrm{~W} \mathrm{~m}^{-2}$, which is in the observed range $\left(-47\right.$ to $\left.-54 \mathrm{~W} \mathrm{~m}^{-2}\right)$ and is close to that in CAM5 $\left(-50.1 \mathrm{~W} \mathrm{~m}^{-2}\right)$. The larger LWP in the MMF model can partly explain why the MMF and CAM5 produce similar shortwave cloud forcing despite that cloud fraction in the MMF is smaller. Simulated longwave cloud forcing is $26.0 \mathrm{~W} \mathrm{~m}^{-2}$, slightly smaller than ERBE $\left(30 \mathrm{~W} \mathrm{~m}^{-2}\right)$ and CERES $\left(29 \mathrm{~W} \mathrm{~m}^{-2}\right.$ ) observations, and is larger than that simulated in CAM5 $\left(21.9 \mathrm{~W} \mathrm{~m}^{-2}\right)$. The larger longwave cloud forcing in the MMF is partly caused by higher ice crystal number concentrations in the MMF, which leads to smaller ice crystal effective radius in the uppermost cloud layers in the upper troposphere (not shown). As the radiative effect of snow particles is included (see the details in Sect. 3.1.2 about its treatment) in both the MMF and CAM5, larger snow water path in the MMF than that in CAM5 $\left(53.4 \mathrm{~g} \mathrm{~m}^{-2}\right.$ in the MMF vs. $45.2 \mathrm{~g} \mathrm{~m}^{-2}$ in CAM5, Table 1) can also lead to the larger longwave cloud forcing.

\subsubsection{Global and zonal distributions}

Figures 1 and 2 show annual average zonal mean latitudepressure cross sections for grid-averaged hydrometeor mass and number concentrations, respectively. Simulated cloud liquid water mass concentrations peak over the tropics and mid-latitude storm tracks at $800-900 \mathrm{hPa}$, which is similar to the distribution of liquid droplet number concentrations, though the latter demonstrates the stronger influence of anthropogenic aerosols as cloud droplet number concentrations are higher in the Northern Hemisphere (NH) than in the Southern Hemisphere (SH). Rain water is more concentrated over the tropics, though rain droplet number concentrations
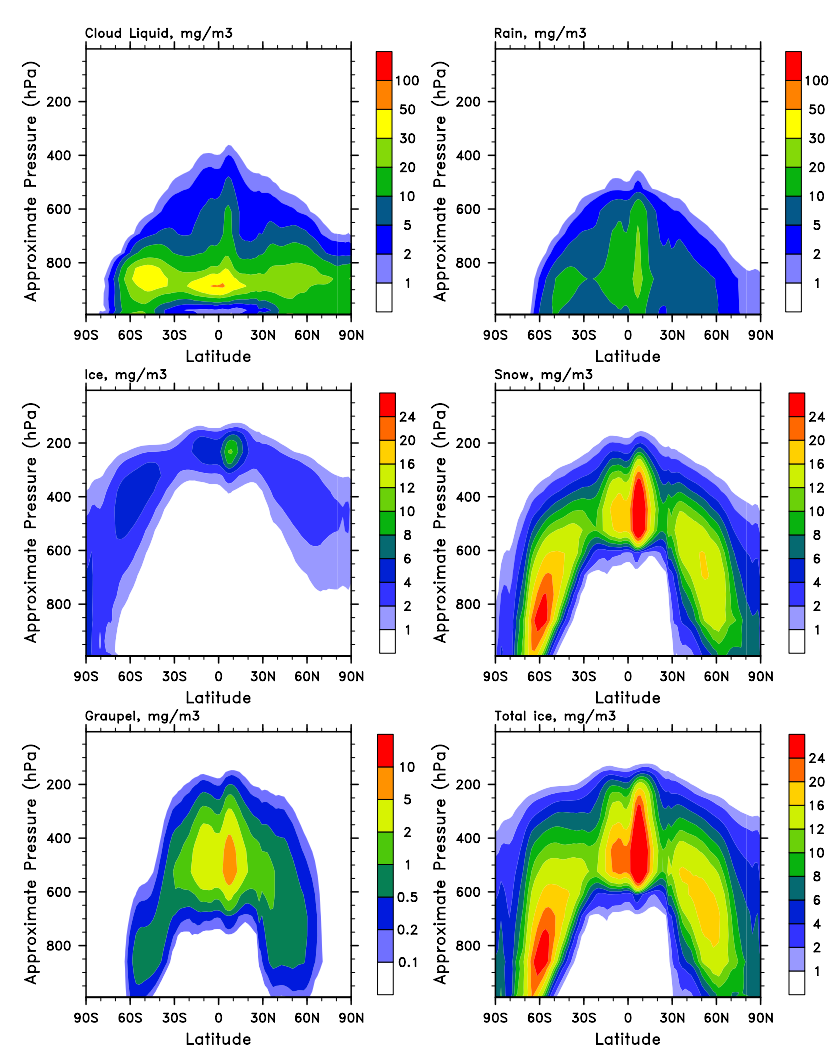

Fig. 1. Annual-averaged zonal-mean grid-mean mass concentrations $\left(\mathrm{mg} \mathrm{m}^{-3}\right)$ of cloud liquid water, rain water, ice water, snow water, graupel water, and total ice water (ice+snow+graupel) in PD in the MMF. The host GCM model (CAM5) uses a hybrid vertical coordinate and the pressure at the $k$ th model level is given by $p(k)=A(k) p_{0}+B(k) p_{s}$, where $p_{s}$ is surface pressure, $p_{0}$ is a specified constant pressure $(1000 \mathrm{hPa})$, and $A$ and $B$ are coefficients. Data are plotted as a function of this hybrid vertical coordinate times 1000, and labelled "Approximate Pressure".

peak over the SH mid-latitudes and over the NH high latitudes, which indicates that rain droplet size is larger over the tropics than over the middle and high latitudes. As cloud formation over the high latitudes is mainly through large-scale cooling or moistening, but not strong convective motions, rain formation over the high latitudes is likely dominated by warm collision-coalescence processes and drizzle from low clouds rather than melting from graupel and snow, which explains why rain mass mixing ratios are low but rain droplet number concentrations are high over the high latitudes.

Simulated cloud ice mass concentrations peak in the upper troposphere over the tropics, while ice crystal number concentrations peak over both the tropics and high latitudes because of colder temperatures over these regions. Snow water mass dominates the total ice water in the MMF model, as we discussed in Sect. 3.1, and graupel has a small contribution to the total ice water. The total ice water distribution shows a peak at $400-500 \mathrm{hPa}$ over the tropics, and two other peaks over the mid-latitude storm track regions, 

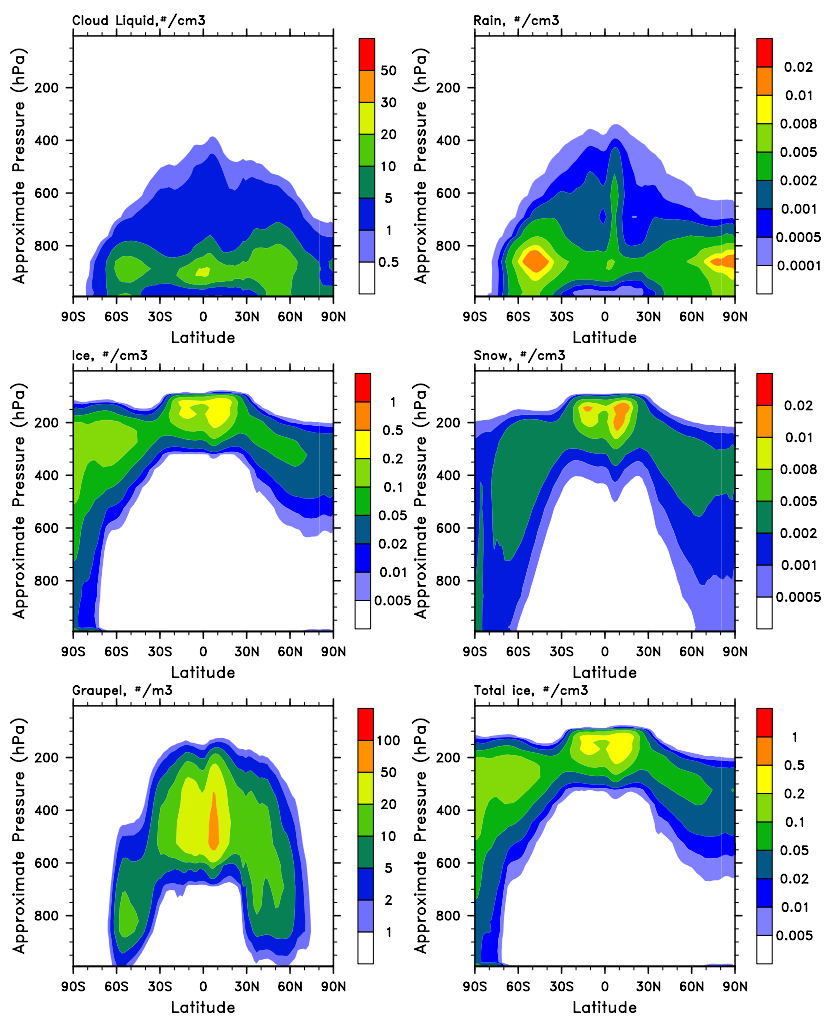

Fig. 2. The same as Fig. 1, but for hydrometeor number concentrations (units: $\mathrm{m}^{-3}$ for grauple, and $\mathrm{cm}^{-3}$ for other hydrometeors).

which are in reasonable agreement with the total ice water distribution from CloudSat (Waliser et al., 2009; Gettelman et al., 2010). The spatial distributions of the different ice hydrometeors are qualitatively similar to those from the NASA fvMMF (Fig. 12 in Waliser et al., 2009), except that the NASA fvMMF simulates a large contribution from graupel.

Figure 3 compares simulated annual-mean total cloud cover with the ISCCP observations. The total cloud cover in the MMF is diagnosed based on column-integrated total cloud water path (liquid + ice) at each CRM column. Columns are considered cloudy if the total cloud water path is larger than $1 \mathrm{~g} \mathrm{~m}^{-2}$ and clear otherwise. The instantaneous total cloud cover is defined as a ratio of cloudy columns to the total number of columns in the CRM (32 in the current setup). The simulated spatial pattern of total cloud cover is in reasonable agreement with observations, but in general, the model underestimates cloud fraction. The underestimation is especially pronounced over regions where low clouds dominate, such as over the subtropical regions in which trade cumulus and stratocumulus are observed. This underestimation, also evident in several previous MMF studies (Khairoutdinov et al., 2005, 2008), is caused in part by the coarse CRM horizontal resolution $(4 \mathrm{~km})$, which makes it difficult to simulate boundary layer clouds in the MMF model. We note that the threshold LWP of $1 \mathrm{~g} \mathrm{~m}^{-2}$ roughly corresponds to a cloud optical depth $(\tau)$

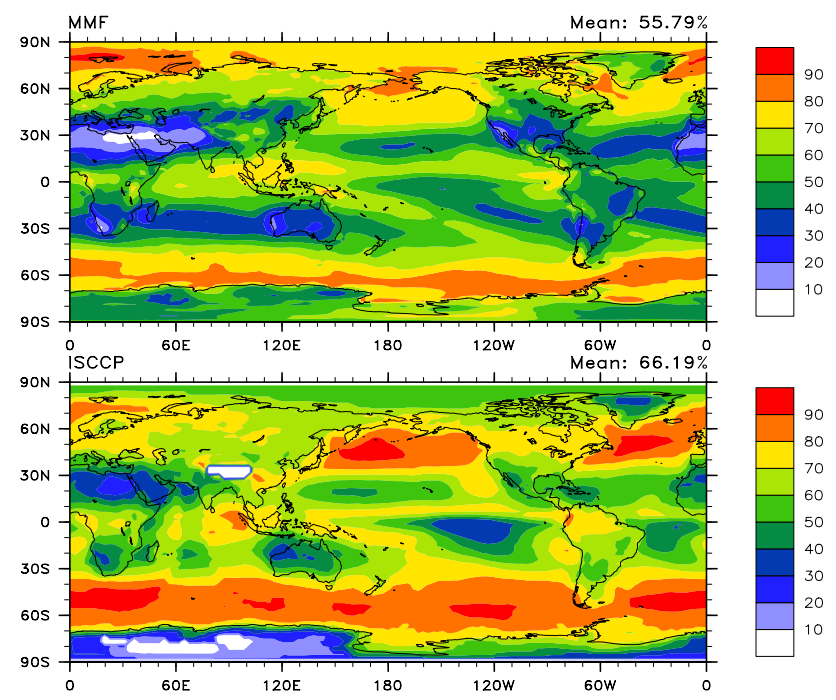

Fig. 3. $\mathrm{PD}$ annual average cloud fraction from the MMF model (upper panel) and from the ISCCP observations (lower panel).

of $0.03-0.1$ with droplet effective radius ( $R_{\text {eff }}$ ) varying from 15 to $5 \mu \mathrm{m}$, based on the following cloud optical depth formula: $\tau=3 \mathrm{LWP} /\left(2 R_{\text {eff }} \times \rho_{\mathrm{W}}\right)$, where $\rho_{\mathrm{W}}$ denotes the liquid water density. This threshold cloud optical depth is smaller than the detection threshold of the ISCCP, which is about 0.3. In future studies, we will apply instrumental simulators to provide a fairer comparison between models and satellite observations (e.g., Marchand and Ackerman, 2010).

Figure 4 compares simulated annual-mean shortwave and longwave cloud forcings with those from the CERES observations. Shortwave (longwave) cloud forcing is defined as the difference between the shortwave (longwave) clearsky and all-sky radiative fluxes at the top of the atmosphere. Annual global mean shortwave cloud forcing in the MMF model is larger than the CERES observation $(-50.5$ vs. $-47.1 \mathrm{~W} \mathrm{~m}^{-2}$ ). The MMF model underestimates shortwave cloud forcing over regions with a large amount of low clouds, such as over the subtropical regions, consistent with the underestimation of cloud cover (Fig. 3), while it overestimates shortwave cloud forcing over the tropics. The longwave cloud forcing in the MMF model is smaller than the CERES observation ( 26.0 vs. $29.9 \mathrm{~W} \mathrm{~m}^{-2}$ ). The radiative effect of snow particles is accounted for in this study, following the same treatment as in CAM5 (Gettelman et al., 2010), and is included in the cloud forcing. The particle shape recipe was based on observations reported in Larson et al. (2006) at $-45^{\circ} \mathrm{C}: 7 \%$ hexagonal columns, $50 \%$ bullet rosettes and $43 \%$ irregular ice particles. A sensitivity test with the MMF model at a coarse GCM resolution $\left(4^{\circ} \times 5^{\circ}\right)$ shows that including the radiative effect of snow increases the shortwave cloud forcing by about $8 \mathrm{~W} \mathrm{~m}^{-2}$ (in the absolute amount) and the longwave cloud forcing by $5 \mathrm{~W} \mathrm{~m}^{-2}$ in January. 

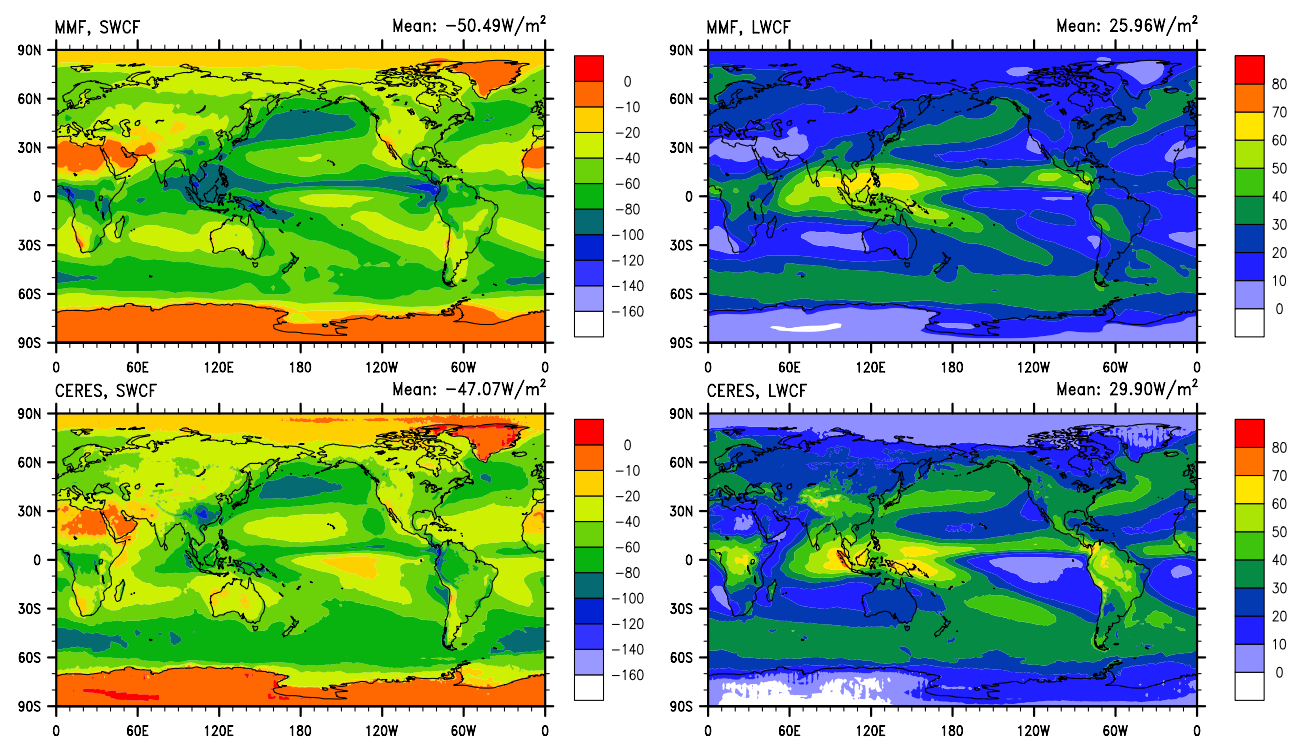

Fig. 4. PD annual average shortwave (left panels) and longwave (right panels) cloud forcing from the MMF model (upper panels) and from the CERES observations (lower panels).
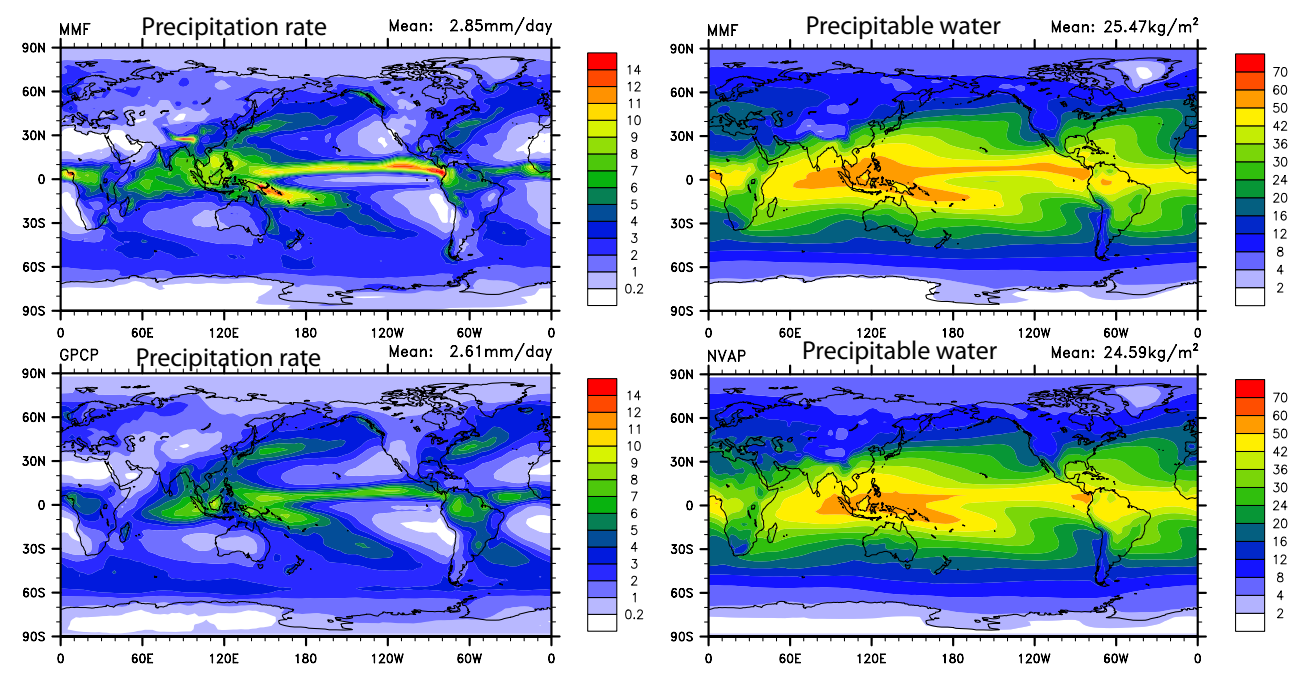

Fig. 5. PD annual average precipitation rate (left panels) and precipitable water (right panels) from the MMF model (upper panels) and from the observations (lower panels: precipitation rate from the GPCP observations and precipitable water from the NVAP observations).

Figure 5 compares simulated annual-mean precipitation rate and precipitable water with observations. The model reproduces the overall features of the observation. However, the model simulates excessive precipitation over the west Indian Ocean, the Maritime continent, Australia, West Pacific, East Pacific in the tropics, and west China. The model underestimates precipitation rates over ocean and over land in the subtropics and mid-latitudes. Simulated global precipitation rate is $2.85 \mathrm{~mm} \mathrm{day}^{-1}$, higher than observations $\left(2.61 \mathrm{~mm} \mathrm{day}^{-1}\right)$. The simulated precipitable water distribution has patterns similar to those in the observations. However, the model overestimates precipitable water over most of the oceans and the Maritime Continent, and underestimates precipitable water over land in the subtropics. The simulation of precipitation and precipitable water by this version of the MMF model is quantitatively similar to the previous version of MMF (Khairoutdinov et al., 2008). The two-moment cloud microphysics coupled with a modal aerosol treatment in this version of the model does little to improve the simulations of precipitation and precipitable water.

Figure 6 compares simulated annual-mean cloud-top droplet number concentration with that from the MODIS satellite retrievals. The satellite data is derived from version 4 of the MODIS by Quaas et al. (2006), assuming 


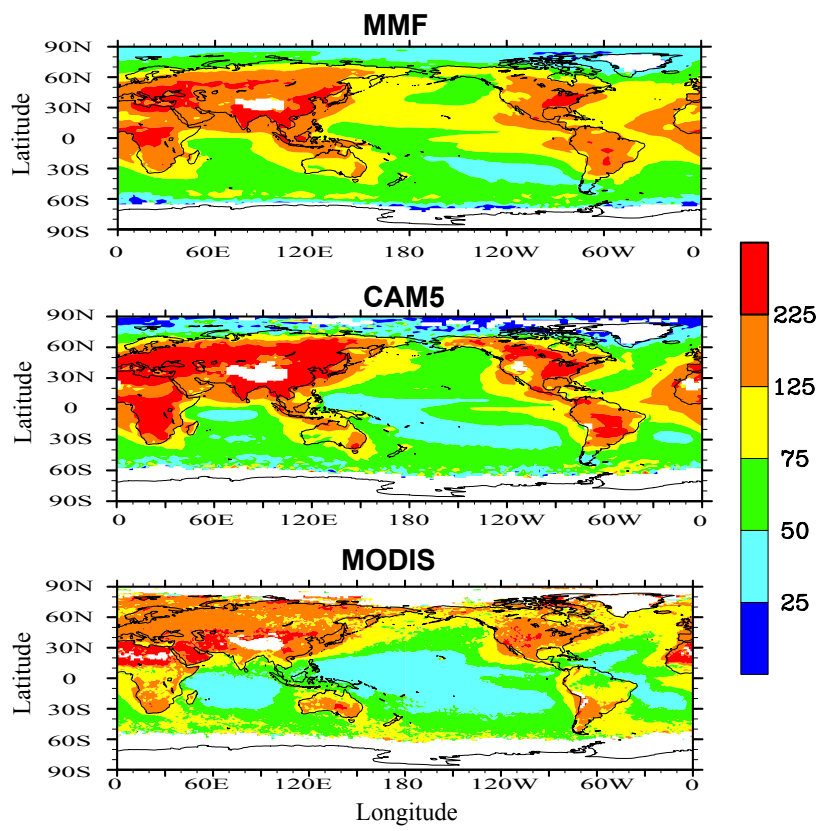

Fig. 6. PD annual-averaged cloud-top droplet number concentrations $\left(\mathrm{cm}^{-3}\right.$ ) derived from the MMF (upper panel), CAM5 (middle panel) and MODIS (lower panel).

adiabatic clouds. For both the satellite and model data, only warm (temperature $>273 \mathrm{~K}$ ) and low level clouds (pressure $>640 \mathrm{hPa}$ ) are sampled. For consistency, the model output is only sampled at the satellite overpass time (13:30 LST). The MMF model reproduces the spatial patterns of the observed cloud-top droplet number concentrations, with larger droplet number concentrations over land than over ocean and over the $\mathrm{NH}$ than over the SH, which clearly demonstrates the influence of anthropogenic aerosols. The patterns in gradients are replicated by both the MMF model as well as observations from the anthropogenic sources over land to its downwind sides over marine environments, e.g., Pacific, Atlantic, and Indian Ocean. The MMF model also simulates enhanced droplet number concentrations over the Southern Ocean (around $50^{\circ} \mathrm{S}$ ), consistent with MODIS observations. However, the MMF model overestimates droplet number concentrations over many oceanic regions, such as the Indian Ocean, the tropical Atlantic Ocean and the tropical Pacific Ocean. In contrast, over the oceanic regions, CAM5 simulates fewer cloud droplets than the MMF, and agrees better with the MODIS observations. On the other hand, over the continental regions, CAM5 simulates more cloud droplets than the MMF and overestimates cloud droplet number concentrations compared with the MODIS observations. The differences in simulated cloud-top droplet number concentrations between CAM5 and the MMF are consistent with the differences in simulated $\mathrm{CCN}$ concentrations discussed in Sect. 3.2.

\subsection{Aerosol fields}

Simulated aerosol fields in the PD simulation were documented and evaluated against observations in Wang et al. (2011) and here we briefly compare the MMF results with CAM5.

The annual, global mean aerosol sources, burdens, and lifetimes are summarized in Table 2. It is not surprising that sea salt and dust burdens are similar in the MMF and CAM5 since dust and sea salt emissions in the MMF are tuned so their burdens match the CAM5 burdens. Simulated BC, POM and SOA burden in the MMF (CAM5) are 0.14 (0.11) Tg, 1.04 (0.77) Tg, and 1.83 (1.40) Tg, respectively. The lower BC, POM and SOA burdens in CAM5 are due to their larger wet removal rates (not shown).

The simulated sulfate burden in the MMF is $1.05 \mathrm{Tg} \mathrm{S}$, which is about twice that in CAM5 $(0.53 \mathrm{Tg} \mathrm{S})$. The lower sulfate burden in CAM5 is partly from a larger wet removal rate, as evident from its shorter lifetime, and partly from smaller sulfate production $\left(42.5 \mathrm{Tg} \mathrm{S} \mathrm{yr}^{-1}\right.$ in CAM5 vs. $59.8 \mathrm{Tg} \mathrm{S} \mathrm{yr}^{-1}$ in the MMF). The latter is caused in part by differences in $\mathrm{SO}_{2}$ wet removal. In the MMF, $\mathrm{SO}_{2}$ wet removal occurs only by rain (which results in little removal below freezing), and the $\mathrm{SO}_{2}$ solubility is based its effective Henry's law equilibrium at $\mathrm{pH}=5$. In $\mathrm{CAM} 5, \mathrm{SO}_{2}$ wet removal occurs by all precipitation, and the $\mathrm{SO}_{2}$ uptake follows that of $\mathrm{H}_{2} \mathrm{O}_{2}$. Both differences produce stronger $\mathrm{SO}_{2}$ wet removal in CAM5. In a sensitivity test (reduced- $\mathrm{SO}_{2}-$ wet-removal), the same wet scavenging treatment of $\mathrm{SO}_{2}$ as that in the MMF is applied to CAM5. This increases the PD sulfate burden in CAM5 by $28 \%$.

Simulated $\mathrm{SO}_{2}$ and sulfate concentrations in the MMF model have been evaluated against observations from the IMPROVE sites in the United States, the EMEP sites in Europe, and the remote ocean network sites operated by the University of Miami in Wang et al. (2011). Table 3 summarizes the model performance in these comparisons, along with the results from CAM5. The MMF model simulates $\mathrm{SO}_{2}$ concentrations in better agreement with observations at the IMPROVE and EMEP sites than CAM5, though the MMF still overestimates $\mathrm{SO}_{2}$ concentrations by a factor of 1-2. Simulated sulfate concentrations are overestimated over the IMPROVE and EMEP sites, and are underestimated over the remote ocean network sites. The MMF model simulates high sulfate concentrations over remote ocean areas and agrees slightly better with observations than CAM5.

Table 4 compares simulated AOD in both the MMF and CAM5 with observational data from the AERONET at sites in East and South Asia, Europe, Northern and Southern Africa, North and South America (See Fig. 22 in Wang et al. (2011) for the scatter plots between the MMF and observations for each region). Both the MMF and CAM5 underestimate AOD over most regions. The MMF model agrees slightly better with observations than CAM5, in terms of both 
Table 2. Global annual budgets of sulfate, BC, POM, SOA, dust and sea salt in the PD and PI simulations of the MMF and CAM5. CAM5 results are in parenthesis. Dust and sea salt budgets are separated into fine mode (Aitken + accumulation) and coarse mode components. Units are days for lifetime, $\mathrm{Tg}$ for burdens and $\mathrm{Tg} \mathrm{yr}^{-1}$ for sources, except for sulfate where units are $\mathrm{Tg} \mathrm{S}_{\mathrm{gnd}} \mathrm{Tg} \mathrm{S} \mathrm{yr}^{-1}$ for burdens and sources.

\begin{tabular}{lrrrrrrrr}
\hline & Sulfate & BC & POM & SOA & Fine Dust & Coarse Dust & Fine Sea Salt & Coarse Sea Salt \\
\hline PD & 59.75 & 7.76 & 50.28 & 103.44 & 75.87 & 2295.20 & 122.82 & 3564.24 \\
source & $(42.47)$ & $(7.76)$ & $(50.28)$ & $(103.44)$ & $(96.44)$ & $(2917.22)$ & $(157.17)$ & $(4627.10)$ \\
PD & 1.05 & 0.14 & 1.04 & 1.83 & 2.00 & 19.40 & 0.88 & 11.29 \\
burden & $(0.53)$ & $(0.11)$ & $(0.77)$ & $(1.40)$ & $(2.00)$ & $(21.64)$ & $(0.95)$ & $(10.77)$ \\
PD & 6.41 & 6.59 & 7.55 & 6.46 & 9.62 & 3.09 & 2.62 & 1.17 \\
lifetime & $(4.55)$ & $(5.14)$ & $(5.59)$ & $(4.94)$ & $(7.57)$ & $(2.71)$ & $(2.21)$ & $(0.85)$ \\
PI & 25.82 & 3.08 & 31.64 & 92.68 & 83.84 & 2536.11 & 124.73 & 3590.88 \\
source & $(15.24)$ & $(3.08)$ & $(31.64)$ & $(92.68)$ & $(101.07)$ & $(3057.35)$ & $(156.49)$ & $(4605.44)$ \\
PI & 0.45 & 0.06 & 0.67 & 1.57 & 2.16 & 21.13 & 0.86 & 11.11 \\
burden & $(0.17)$ & $(0.04)$ & $(0.46)$ & $(1.21)$ & $(2.07)$ & $(22.63)$ & $(0.92)$ & $(10.63)$ \\
PI & 6.36 & 7.11 & 7.73 & 6.18 & 9.40 & 3.04 & 2.52 & 1.13 \\
lifetime & $(4.07)$ & $(4.74)$ & $(5.31)$ & $(4.77)$ & $(7.48)$ & $(2.70)$ & $(2.15)$ & $(0.84)$ \\
PD/PI & 1.01 & 0.93 & 0.98 & 1.04 & 1.02 & 1.01 & 1.04 & 1.02 \\
lifetime & $(1.12)$ & $(1.09)$ & $(1.05)$ & $(1.04)$ & $(1.01)$ & $(1.00)$ & $(1.03)$ & $(1.01)$ \\
\hline
\end{tabular}

Table 3. Observed means, normalized mean biases $(b)$ and correlation coefficients $(R)$ between models and observations for $\mathrm{SO}_{2}$, and $\mathrm{SO}_{4}$. Annual average data is used. Observations are from the United States Interagency Monitoring of Protected Visual Environment (IMPROVE) sites (http://vista.cira.colostate.edu/improve/), the European Monitoring and Evaluation Programme (EMEP) sites (http://www.emep.int), and the ocean network sites operated by the Rosenstiel School of Marine and Atmospheric Science (RSMAS) at the University of Miami (Prospero et al., 1989; Savoie et al., 1989, 1993; Arimoto et al., 1996). See Figs. 9-10 in Wang et al. (2011) for the scatter plots of MMF results versus observations.

\begin{tabular}{lrrrrr}
\hline & $\mathrm{SO}_{2}$ from IMPROVE & $\mathrm{SO}_{2}$ from EMEP & $\mathrm{SO}_{4}$ from IMPROVE & $\mathrm{SO}_{4}$ from EMEP & $\mathrm{SO}_{4}$ from RSMAS \\
\hline Obs (mean) & 0.30 & 0.77 & 1.59 & 2.37 & 0.94 \\
MMF b & 1.7 & 0.45 & 0.33 & 0.07 & -0.10 \\
CAM5 b & 2.7 & 1.06 & 0.38 & 0.01 & -0.33 \\
MMF R & 0.59 & 0.72 & 0.95 & 0.79 & 0.95 \\
CAM5 R & 0.56 & 0.68 & 0.96 & 0.74 & 0.97 \\
\hline
\end{tabular}

normalized mean bias and correlation coefficients with observations.

Figure 7 shows aerosol size distributions in the marine boundary layer. The observational data are from Heintzenberg et al. (2000) and were compiled and aggregated onto a $15^{\circ} \times 15^{\circ}$ grid. The model output is sampled over the same regions as observations. Aerosol size distributions simulated by both the MMF and CAM5 are in reasonable agreement with observations, and show bimodal distributions in most regions. Simulated aerosol number concentrations in the MMF are higher than that in CAM5 and agree better with observations. Higher aerosol number concentrations in the MMF are consistent with its higher global aerosol burdens (Table 2). We note that cloud-top droplet number concentrations over the oceanic regions in CAM5 are lower than those in the MMF and agree better with the MODIS observation
(Fig. 6 in Sect. 3.1), which seems not consistent with the comparison shown in Fig. 7. However, the spatial and temporary coverage between satellite and field observations is different (e.g., field observations only cover a particular period, while MODIS has multi-year continuous observations). Moreover, the aerosol size distribution observations in Fig. 7 were made near the surface, while cloud droplet number concentration from MODIS is at cloud top. These differences make it challenging to establish consistent pictures among different comparisons.

Figure 8 shows monthly BC concentrations at four sites in the polar regions. $\mathrm{BC}$ concentrations in the $\mathrm{MMF}$ are in reasonable agreement with observations, in terms of both magnitudes and seasonal cycles. In contrast, CAM5 underestimates $\mathrm{BC}$ concentrations by 1-2 orders of magnitude in the polar regions. What is more, CAM5 does not capture the 
Table 4. Observed means, normalized mean biases $(b)$ and correlation coefficients $(R)$ between the model and observations for AOD over seven different regions (North America, Europe, East Asia, North Africa, and South Africa, South Asia) and the global. Monthly mean data is used. Observations are from the AERONET sites (http://aeronet.gsfc.nasa.gov/). See Fig. 22 in Wang et al. (2011) for the scatter plots of MMF results versus observations.

\begin{tabular}{lrrrrrrrr}
\hline & $\begin{array}{r}\text { North } \\
\text { America }\end{array}$ & Europe & $\begin{array}{r}\text { East } \\
\text { Asia }\end{array}$ & $\begin{array}{r}\text { North } \\
\text { Africa }\end{array}$ & $\begin{array}{r}\text { South } \\
\text { Africa }\end{array}$ & $\begin{array}{r}\text { South } \\
\text { America }\end{array}$ & $\begin{array}{r}\text { South } \\
\text { Asia }\end{array}$ & Global \\
\hline Obs (mean) & 0.13 & 0.18 & 0.34 & 0.51 & 0.18 & 0.21 & 0.39 & 0.21 \\
MMF b & 0.10 & -0.24 & -0.35 & -0.20 & -0.30 & 0.03 & -0.47 & -0.13 \\
CAM5 b & -0.14 & -0.37 & -0.46 & -0.27 & -0.25 & 0.03 & -0.62 & -0.24 \\
MMF R & 0.91 & 0.37 & 0.37 & 0.37 & 0.67 & 0.51 & 0.56 & 0.74 \\
CAM5 R & 0.88 & 0.22 & 0.32 & 0.38 & 0.58 & 0.51 & 0.77 & 0.69 \\
\hline
\end{tabular}

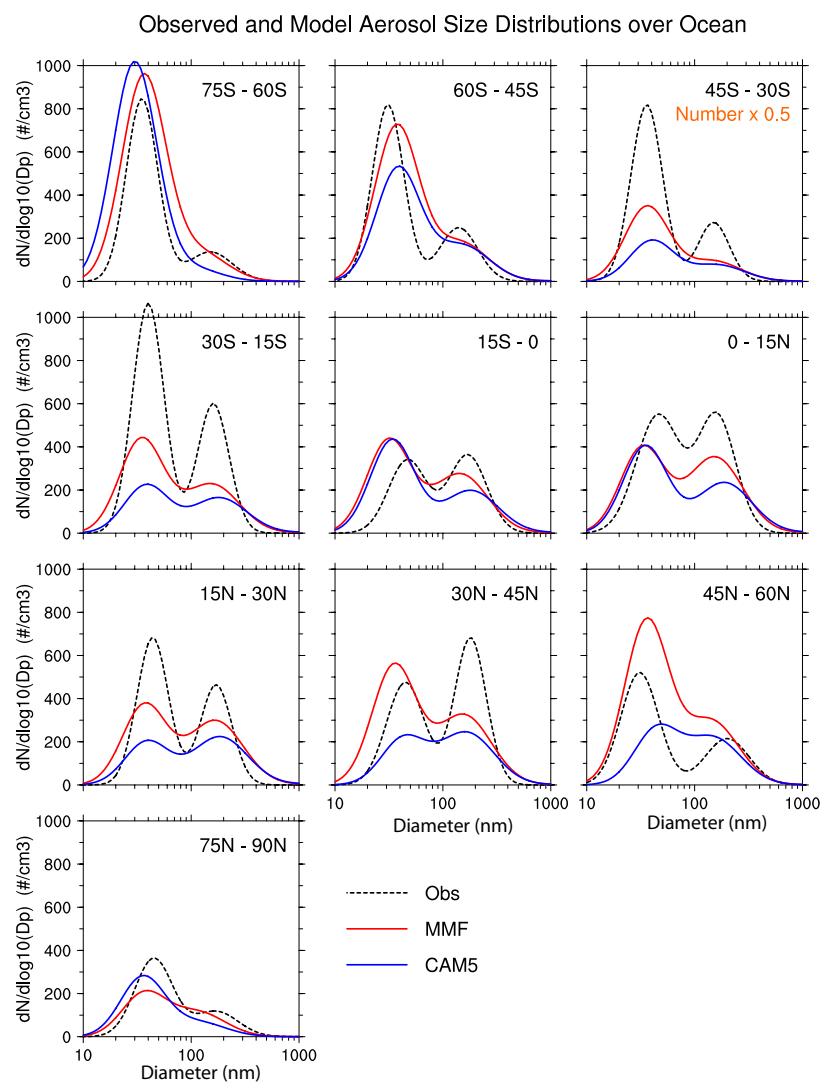

Fig. 7. PD aerosol size distributions in the marine boundary layer from the MMF, CAM5, and observations. Observations (Obs) are from Heintzenberg et al. (2000). For the $45^{\circ} \mathrm{S}-30^{\circ} \mathrm{S}$ latitude band, aerosol number density is scaled by 0.5 so the same y axis can be used for all latitude bands.

observed seasonal cycle. Simulated sulfate aerosols over the Arctic in the MMF demonstrate a similar improvement over CAM5 (not shown).

Figure 9 shows the annual mean global distribution of CCN concentrations (at $0.1 \%$ supersaturation) averaged over the lowest 8 model levels (surface to about $800 \mathrm{hPa}$ ) in both
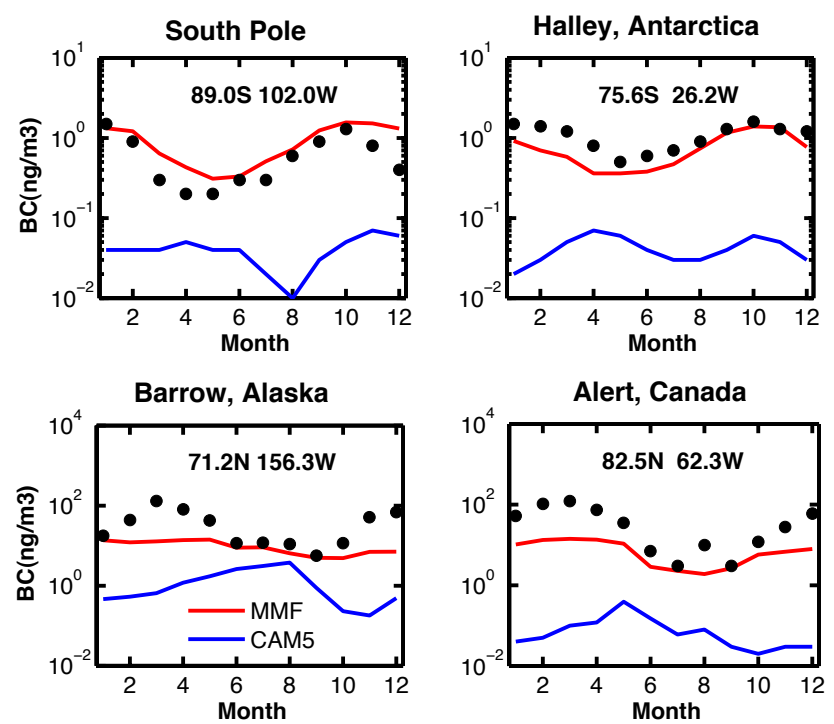

Fig. 8. Monthly-average $\mathrm{BC}$ concentrations at four polar sites: (a) Amundsen-Scott, South Pole (Bodhairne, 1995); (b) Halley, Antarctica (Wolff and Cachier, 1998); (c) Barrow, Alaska (Bodhaine, 1995); and (d) Alert, Canada (Hopper et al., 1994). PD model results are in solid lines (red: MMF; blue: CAM5), and observed data are in dots.

the MMF and CAM5. The spatial patterns of CCN concentrations are similar in the MMF and CAM5, with high concentrations over strongly polluted regions, and low concentrations over remote regions. However, the MMF produces lower $\mathrm{CCN}$ concentrations in the strongly polluted regions and higher $\mathrm{CCN}$ concentrations in the remote regions, such as remote oceanic regions and polar latitudes, than CAM5. The higher CCN concentrations in the polar latitudes in the MMF can also be seen in the annual zonal distribution shown in Fig. 10, which is consistent with higher aerosol concentrations in the polar latitudes discussed above (Fig. 8). It is also evident in Fig. 10 that the MMF produces higher $\mathrm{CCN}$ concentrations at high altitudes than CAM5. Differences in convective transport, wet scavenging in stratiform 

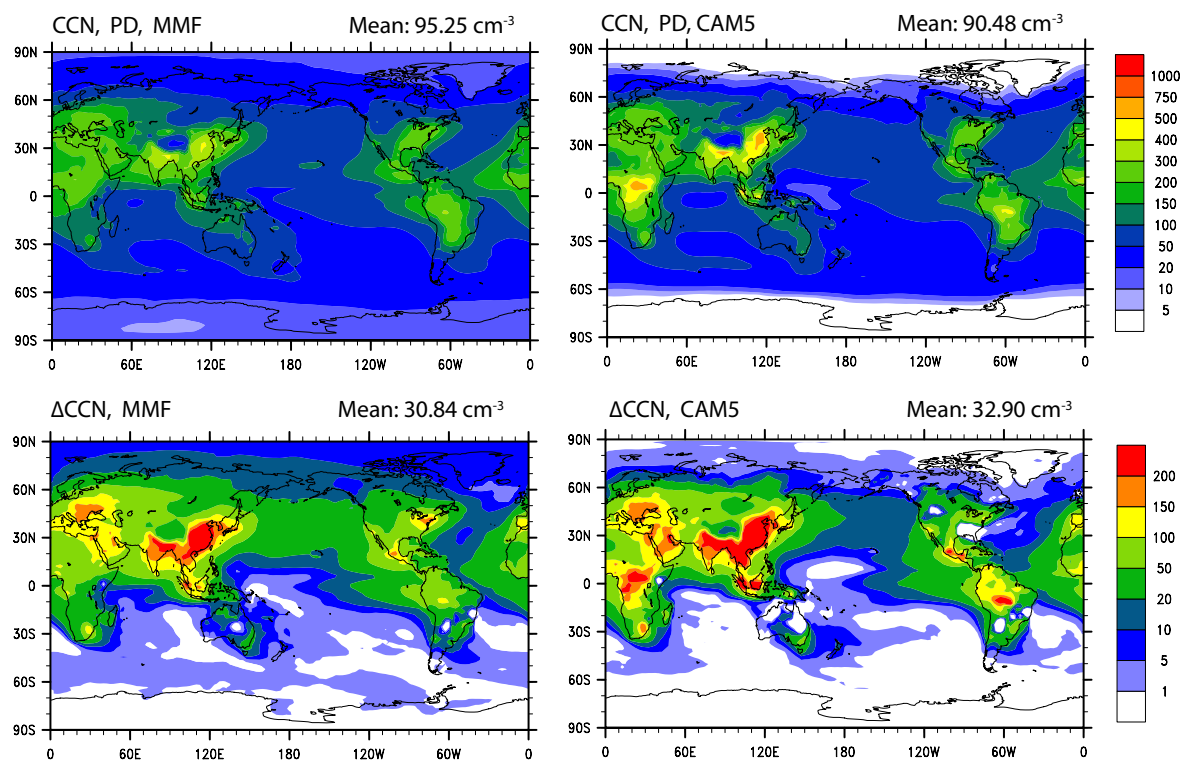

$\triangle C C N / C C N P I, M M F$

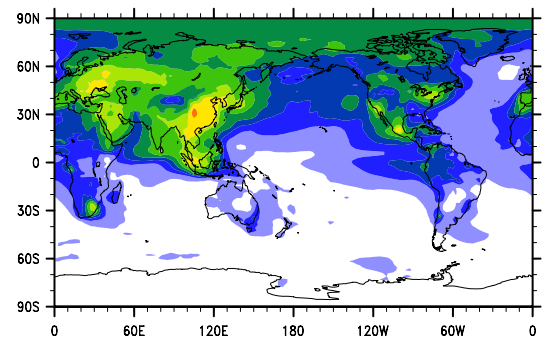

$\triangle C C N / C C N P I, C A M 5$

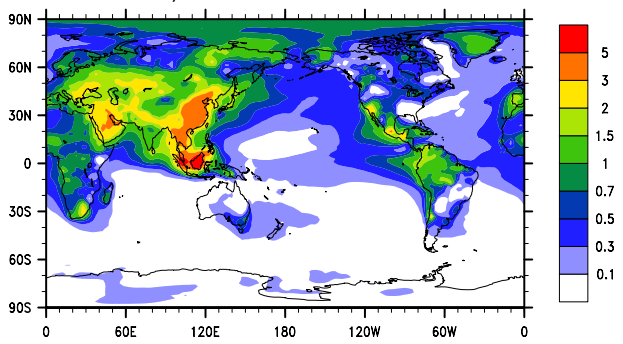

Fig. 9. Annual-averaged global distribution of $\mathrm{CCN}$ concentrations at $0.1 \%$ supersaturation averaged over the lowest 8 model levels (surface to about $800 \mathrm{hPa}$ ) in the PD simulations (top panels), the difference between PD and PI (PD-PI) (middle panels), and the relative differences between PD and PI [(PD-PI)/PI] (bottom panels) in both the MMF (left panels) and CAM5 (right panels).
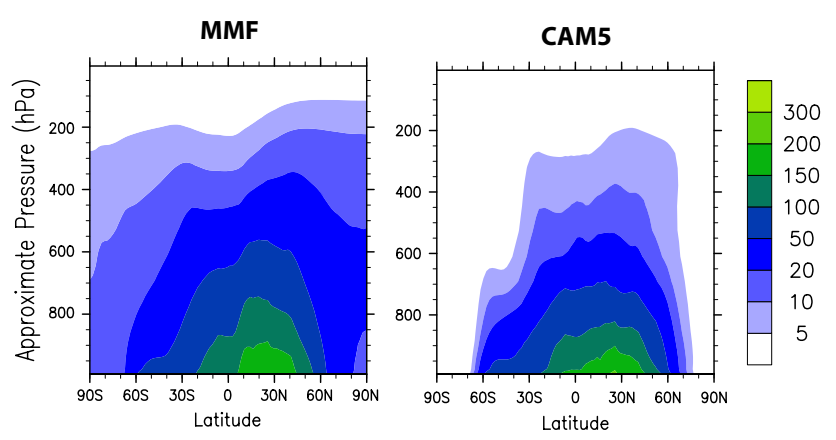

Fig. 10. Annual-averaged zonal-mean $\mathrm{CCN}$ concentrations at $0.1 \%$ supersaturation in the PD simulations in the MMF (left panel) and CAM5 (right panel).

and convective clouds, and long range transport between the MMF model and CAM5 may lead to these differences. Further studies are needed to identify the causes for the differences between the MMF and CAM5.

\section{Aerosol indirect effects}

\subsection{Aerosol-cloud relationships in the PD}

Following Quaas et al. (2009), the strength of aerosol-cloud interactions (ACI) is defined as the relative change in cloud properties with respect to the relative change in aerosol optical properties, and is calculated as:

$\mathrm{ACI}=\frac{d \ln C}{d \ln A}$,

where $C$ is a cloud parameter (e.g., cloud droplet number concentration, cloud LWP, or cloud fraction), and $A$ is a proxy for column-integrated CCN concentrations. Quaas et al. (2009) used AOD as the proxy for column-integrated $\mathrm{CCN}$ concentrations. Aerosol Index (AI), which is the product of AOD and Ångström coefficient, has also been used in some previous studies as a surrogate for the columnintegrated $\mathrm{CCN}$ concentrations. Compared to AOD, AI is more representative of the column-integrated $\mathrm{CCN}$ concentrations since the Ångström coefficient accounts for the particle size with smaller Ångström coefficients for larger size 


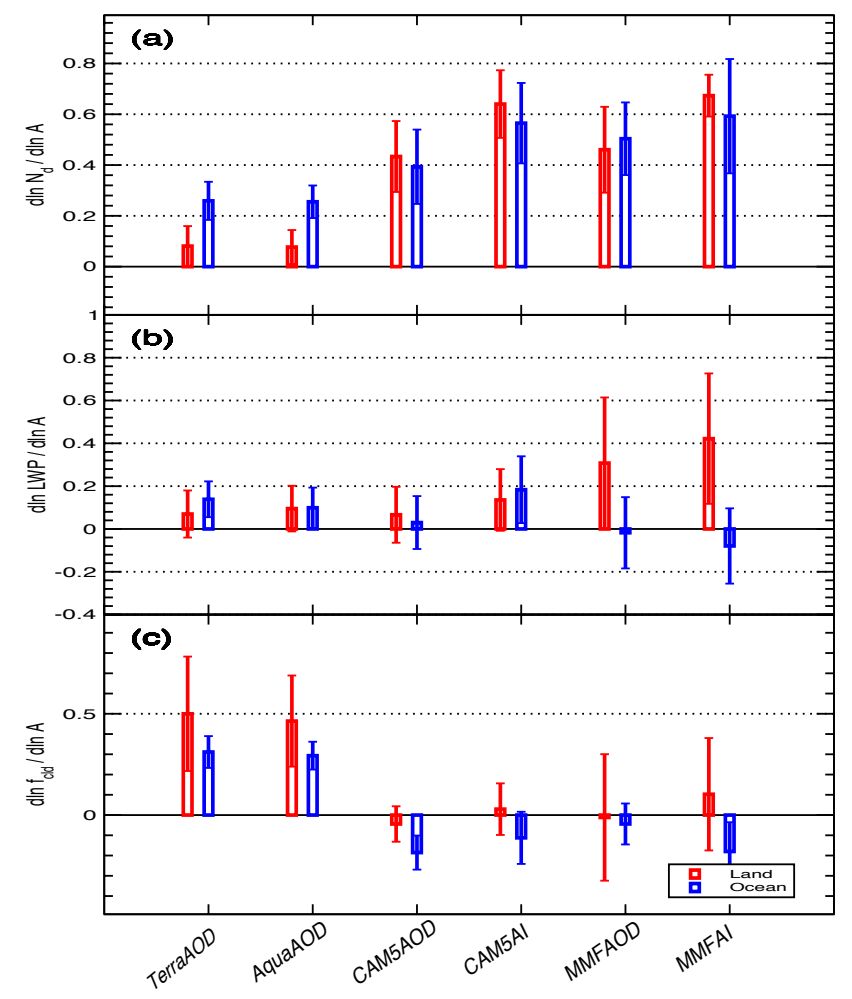

Fig. 11. Sensitivities of (a) cloud-top droplet number concentration, (b) cloud liquid water path, (c) cloud fraction to perturbations in column-integrated aerosol number concentration proxies represented by either AOD or AI as obtained from the linear regressions in PD. The weighted averages for four seasons and all six land regions (red) and eight ocean regions (blue) are show, with the variability as error bar. Results are shown for MODIS Terra (TerraAOD: cloud parameters vs. AOD); MODIS Aqua (AquaAOD: cloud parameters vs. AOD); CAM5 (CAM5AOD: cloud parameters vs. AOD, CAM5AI: cloud parameters vs. AI); MMF (MMFAOD: cloud parameters vs. AOD, MMFAI: cloud parameters vs. AI).

particles (Nakajima et al., 2001). Here both AOD and AI are used as proxies for the column-integrated $\mathrm{CCN}$ concentrations to calculate $\mathrm{ACI}$ in the MMF model for cloud droplet number concentrations, LWP, and cloud fraction, following the same approach as that in Quaas et al. (2009). ACI is obtained by a linear regression between $\ln C$ and $\ln A$. Model output is sampled daily at 01:30 p.m. local time to match the MODIS Aqua equatorial crossing time. The model output is interpolated to a $2.5^{\circ} \times 2.5^{\circ}$ regular longitude-latitude grid as in Quaas et al. (2009), to facilitate the direct comparison between the current study and Quaas et al. (2009). The regressions for the MMF and CAM5 simulations are performed separately for fourteen different ocean and land regions and four seasons as in Quaas et al. (2009). We compare the MMF results with those from the standard CAM5, and those from the observations and other model results in Quaas et al. (2009).
Figure 11 shows the mean sensitivities of cloud parameters to column aerosol properties for all seasons in both the land and ocean areas from the satellite data, and from the MMF and CAM5 simulations, with the error bars showing the variability among 6 land or 8 ocean regions and 4 seasons. Cloud-top droplet number concentration increases with increasing AOD in both models and satellite observations (Fig. 11a). Simulated slopes between cloud-top droplet number concentration and AOD in the MMF and CAM5 are similar, with a slightly larger slope in the MMF, and are significantly larger than that in satellite observations. We note that half of the global climate models included in Quaas et al. (2009) overestimated the slope. Replacing AOD with AI in the MMF and CAM5 further increases the slope, which is consistent with McComiskey et al. (2009).

The slope between LWP and AOD is positive over land in the MMF model, consistent with those in satellite observations and CAM5, but the magnitude is larger in the MMF than in the satellite observations and in CAM5. In contrast, LWP and AOD over ocean are negatively correlated in the MMF, which is opposite to those in CAM5 and the MODIS retrievals. Replacing AOD with AI leads to larger negative/positive slope over ocean/land for the MMF. Both positive and negative correlations between LWP and AOD/AI have been observed (Platnick et al., 2000; Coakley and Walsh, 2002; Kaufman et al., 2005; Matsui et al., 2006). Using a global CRM with on-line aerosols, Suzuki et al. (2008) also obtained a negative correlation between LWP and AI from an 8-day integration in July. The positive correlation between LWP and AOD/AI is attributed to cloud lifetime effects from aerosols or/and aerosol swelling effects in the high relative humidity regions surrounding clouds. The negative correlation between LWP and AOD/AI can be attributed to rain wash-out effects (Suzuki et al., 2004), semidirect effects (Hansen et al., 1997), or dynamical feedbacks such as enhanced entrainment of drier air or enhanced evaporation of the more numerous smaller cloud droplets in polluted clouds (Ackerman et al., 2004; Jiang et al., 2006). Our results suggest that the negative effect dominates over ocean while the positive effect dominates over land in the MMF model.

Simulated cloud fraction and AOD are negatively correlated in the MMF and CAM5, opposite to the correlation found in the satellite retrievals, though using AI instead of AOD leads to a slightly positive correlation over land in both models. The positive correlation in satellite data can be attributed to the swelling of aerosol particles near clouds, cloud lifetime effects from aerosols, or the contamination in AOD retrievals by clouds. Quaas et al. (2010) showed that the positive correlation between cloud fraction and AOD in their model can largely be attributed to the aerosol swelling effects, and a negative correlation is found when dry AOD is used. The negative correlation between cloud fraction and AOD in CAM5 and the MMF may indicate the stronger scavenging effects of clouds on aerosols and/or less swelling 

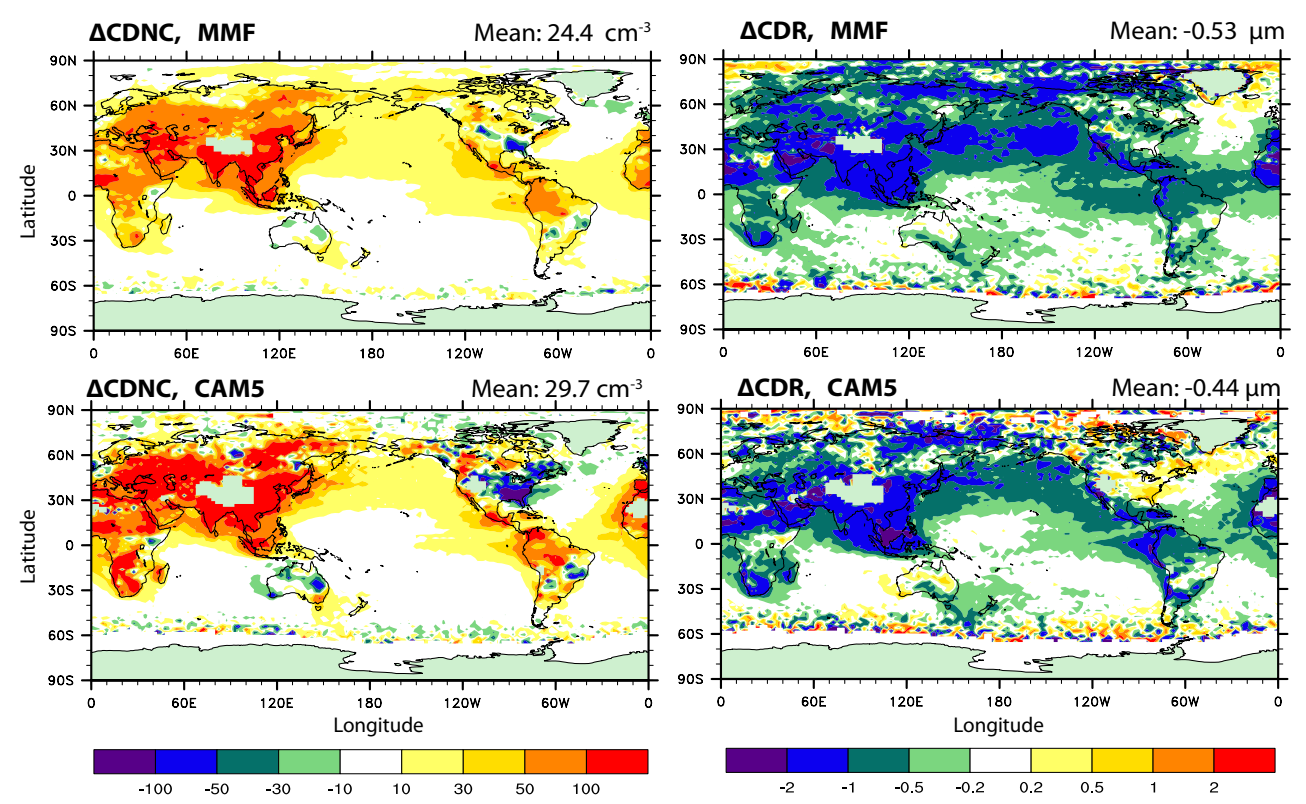

Fig. 12. Annual-average changes (PD-PI) in cloud-top droplet number concentrations (upper panels) and cloud-top droplet effective radius (lower panels) between the PD and PI simulations for low level (pressure $>640 \mathrm{hPa}$ ), warm clouds (cloud top temperature warmer than $273.16 \mathrm{~K}$ ) in the MMF (upper panel) and CAM5 (lower panel).

effects of clouds on aerosols in both models. We note that the MMF AOD is from the clear-sky CRM columns and therefore may be less susceptible to the swelling effects than CAM5 AOD.

\subsection{Anthropogenic aerosol effects}

\subsubsection{Anthropogenic aerosol effects in the MMF}

As summarized in Table 2, simulated aerosol loadings have increased significantly since preindustrial time. Globally, sulfate, BC, POM, and SOA burdens increase by $133 \%$, $133 \%, 55 \%$, and $17 \%$, respectively from the PI to PD. Dust and sea salt burden are similar in both PI and PD simulations. The lifetimes of sulfate, SOA, dust and sea salt increase slightly from PI to PD, which may be caused in part by cloud lifetime effects from aerosols (more aerosols lead to longer cloud lifetime, and therefore less efficient wet removal in PD than in PI), a positive feedback in aerosol indirect effects. On the other hand, the lifetimes of $\mathrm{BC}$ and POM decrease from PI to PD, which may be caused in part by enhanced sulfate coating on $\mathrm{BC}$ and $\mathrm{POM}$ and therefore enhanced wet removal of $\mathrm{BC}$ and POM in the PD.

Figure 12 shows the global distribution of changes in annual-mean cloud-top droplet number concentrations (CDNC) and cloud-top droplet effective radius (CDR) between the PD and the PI simulations (PD-PI). Cloud-top droplet number concentrations increase from the PI to PD simulations over most regions, and increases in cloud-top droplet number concentrations are mainly located in the source regions of fossil fuel burning (e.g., more than $50 \mathrm{~cm}^{-3}$ in Europe, East and South Asia) and biomass burning (e.g., more than $30 \mathrm{~cm}^{-3}$ in Africa and South America), and downwind of the source regions (e.g., between $10-30 \mathrm{~cm}^{-3}$ in the mid-latitude Pacific and the tropical Atlantic). Decreases in droplet number concentrations are simulated in some regions, such as Southeast United States, central South America, and North Australia, which are caused by reduced biomass burning emissions from PI to PD (not shown). Cloud-top droplet effective radius decreases from the PI to PD simulations over most regions, by more than $1 \mu \mathrm{m}$ over strongly polluted regions (e.g., East and South Asia) and more than $0.5 \mu \mathrm{m}$ over many oceanic regions (e.g., the North Pacific). The spatial pattern of changes in droplet effective radius is consistent with the spatial pattern of changes in cloud-top droplet number concentrations (i.e., large increases in droplet number concentrations lead to large decreases in droplet effective radius).

Figure 13 shows the zonal distribution of changes in AOD, cloud liquid water path (LWP), CDR, CDNC, shortwave cloud forcing (SWCF), and net total fluxes (shortwave+longwave) at the top of the atmosphere (FSNT+FLNT) between the PD and PI simulations. Increases in AOD from the anthropogenic aerosols are mainly located north of $30^{\circ} \mathrm{S}$, and peak in the $\mathrm{NH}$ mid-latitudes with a value of about 0.04 . Increases in cloud-top droplet number concentrations closely follow the changes in AOD, with a peak of about $40 \mathrm{~cm}^{-3}$ in the NH mid-latitudes. Decreases in cloud-top droplet effective radius are larger over the NH mid-latitudes, consistent with the large increases 

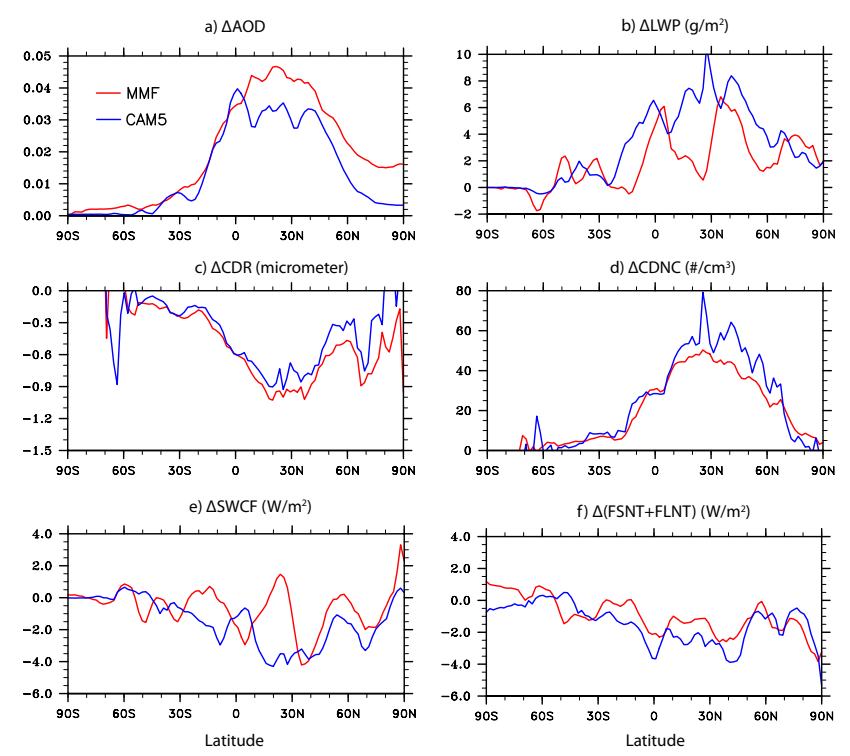

Fig. 13. Change in the zonal-mean annual-average (a) AOD, (b) liquid water path (LWP), (c) cloud top droplet effective radius (CDR), (d) cloud top droplet number concentrations (CDNC); (e) shortwave cloud forcing (SWCF); and (f) net total flux at the top of the atmosphere (FSNT+FLNT) from anthropogenic aerosols in both the MMF (red lines) and CAM5 (blue lines) simulations.

in cloud-top droplet number concentration, and also larger over the NH high latitudes, which can be explained by the large relative changes in cloud-top droplet number concentrations. Increases in LWP are large over the tropics and the $\mathrm{NH}$ mid-latitudes, which is consistent with the increases in cloud droplet number concentrations over these regions. On the other hand, changes in LWP in the NH subtropics and the latitude bands around $60^{\circ} \mathrm{N}$ are small though changes in cloud-top droplet number concentrations are large over these regions. Increases in the shortwave cloud forcing (in the absolute amount) are caused by both decreases in droplet effective radius and increases in LWP, while its changes follow more closely with changes in LWP than with changes in droplet effective radius (e.g., smaller changes in the $\mathrm{NH}$ subtropics and around $60^{\circ} \mathrm{N}$ ). The positive change in shortwave cloud forcing at around $20^{\circ} \mathrm{N}$ is caused by a decrease in cloud fraction (not shown). Changes in net total fluxes at the top of the atmosphere are larger in the $\mathrm{NH}$ than in the $\mathrm{SH}$.

The global mean changes from the PI to PD simulations are summarized in Table 5. Globally, anthropogenic aerosols lead to a 0.024 increase in clear-sky AOD, a $24 \mathrm{~cm}^{-3}$ increase in cloud-top droplet number concentrations, a $0.52 \mu \mathrm{m}$ decrease in cloud-top droplet effective radius, and a $2.11 \mathrm{~g} \mathrm{~m}^{-2}$ increase in LWP. A cooling of $0.77 \mathrm{~W} \mathrm{~m}^{-2}$ in shortwave cloud forcing is simulated, which results from the decreases in cloud droplet effective radius and increases in liquid water path. As expected, simulated longwave cloud forcing has little change between the PD and PI simulations since aerosol effects on ice clouds are not accounted for in this version of the MMF model. Simulated total aerosol effect on the shortwave fluxes at the top of the atmosphere is $-1.31 \mathrm{~W} \mathrm{~m}^{-2}$. The aerosol effect in the clear-sky (assuming entirely clear grid boxes) is $-0.54 \mathrm{~W} \mathrm{~m}^{-2}$. The simulated aerosol effect on the net total fluxes (shortwave + longwave) is $-1.05 \mathrm{~W} \mathrm{~m}^{-2}$, with a longwave contribution of $0.26 \mathrm{~W} \mathrm{~m}^{-2}$. The longwave warming of $0.26 \mathrm{~W} \mathrm{~m}^{-2}$ is mainly from the contribution in the clear sky, which is caused in part by cooling over land surface (surface temperature over land decreases by $0.34 \mathrm{~K}$ ) and therefore less thermal emission from land.

\subsubsection{Comparison with CAM5}

In the standard version of CAM5, the simulated PI to PD change in shortwave cloud forcing is $-1.79 \mathrm{~W} \mathrm{~m}^{-2}$, the change in longwave cloud forcing is $0.37 \mathrm{~W} \mathrm{~m}^{-2}$, the aerosol direct effect in shortwave fluxes in the clear sky (taking into account entirely clear grid boxes) is $-0.45 \mathrm{~W}^{-2}$, and the aerosol effect on the net total fluxes (FSNT + FLNT) is $-1.66 \mathrm{~W} \mathrm{~m}^{-2}$. The larger clear-sky direct effect in the MMF than in CAM5 $\left(-0.54 \mathrm{~W} \mathrm{~m}^{-2}\right.$ in the MMF vs. $-0.45 \mathrm{~W} \mathrm{~m}^{-2}$ in CAM5) can be explained in part by the larger increase in sulfate burden from PI to PD in the MMF $(0.60 \mathrm{Tg} S)$ than in CAM5 $(0.36 \mathrm{Tg} \mathrm{S})$. We also noted that aerosol water uptake in the MMF is calculated at each CRM grid cell with a CRMscale relative humidity, while aerosol water uptake in CAM5 is calculated at each GCM grid cell with a GCM-scale clearsky relative humidity. This may be another reason why the MMF simulates the larger clear-sky direct effects, since including subgrid variations in the relative humidity can lead to larger aerosol direct effects because of the nonlinear dependence of aerosol water uptake on relative humidity (Haywood et al., 1997).

The simulated change in shortwave cloud forcing in the MMF $\left(-0.77 \mathrm{~W} \mathrm{~m}^{-2}\right)$ is much smaller than that in CAM5 $\left(-1.79 \mathrm{~W} \mathrm{~m}^{-2}\right)$, despite the fact that changes in AOD and cloud-top droplet effective radius from anthropogenic aerosols in the MMF are slightly larger than those in CAM5 (Table 3 and Figs. 12-13). For example, the global, annual mean change in cloud-top droplet effective radius is $-0.53 \mu \mathrm{m}$ in the MMF simulations, compared with $-0.45 \mu \mathrm{m}$ in the CAM5 simulations (Table 3 and Fig. 12).

The smaller change in shortwave cloud forcing in the MMF is consistent with its smaller change in liquid water path (LWP) between the PI and PD simulations (Fig 13b). Globally, an increase of $3.9 \%$ in LWP from PI to PD is simulated in the MMF, which is about one-fourth of the change of $15.6 \%$ in LWP in stratiform clouds (and about half of the change of $8.8 \%$ in total LWP) in CAM5. Regionally, the LWP in stratiform clouds in CAM5 increases by more than $50 \%$ over many continental regions with strong anthropogenic emissions (e.g., East Asia, South Asia, the Maritime Continent, and Europe) and increases by more than $20 \%$ 

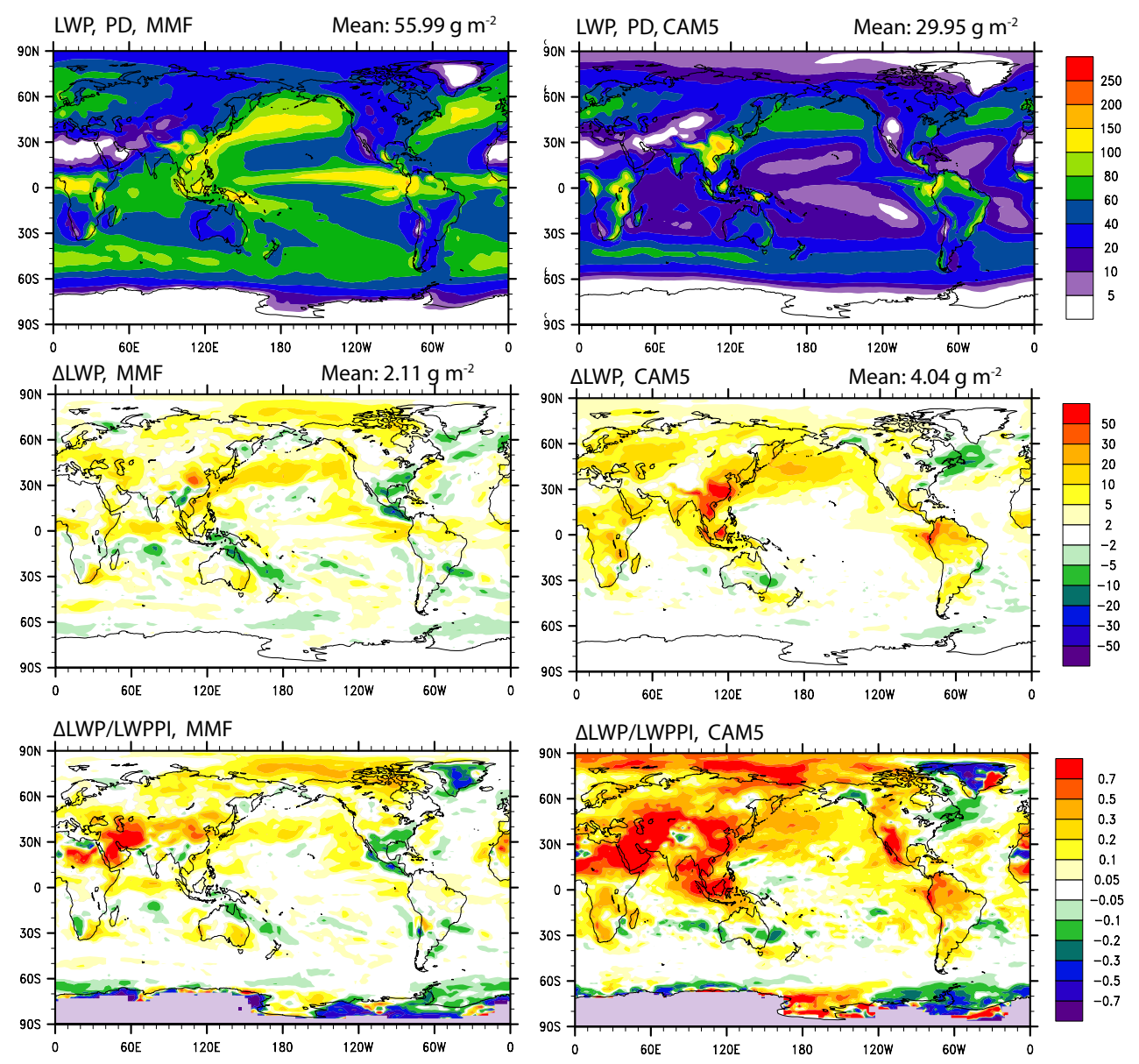

Fig. 14. Annual-averaged global distribution of liquid water path (LWP) in the PD simulations (top panels), the difference between PD and PI (PD-PI) (middle panels), and the relative differences between PD and PI [(PD-PI)/PI] (bottom panels) in both the MMF (left panels) and CAM5 (right panels). Liquid water path in CAM5 is from large-scale clouds only and does not include contributions from convective clouds.

over some oceanic regions such as the North Pacific Ocean (Fig. 14). In contrast, the increase in LWP in the MMF is much weaker, less than $30 \%$ over most continental regions, and less than $10 \%$ over most oceanic regions. It is evident in Fig. 13 that the large differences in simulated aerosol indirect effects between the MMF and CAM5 occur over the regions where the differences in changes of LWP are larger such as over the NH subtropics (compare Fig. 13e to b). The scatter plots of the relative change in LWP and in shortwave cloud forcing shown in Fig. 15 further demonstrate that the larger change in LWP in CAM5 leads to the larger change in shortwave clouds forcing.

The much smaller increase in LWP in the MMF is caused primarily by a much smaller response in LWP to a given CCN perturbation from PI to PD as shown in Fig. 16a-b. The slope between the relative change in LWP and the relative change in $\mathrm{CCN}$ from the linear regression is 0.11 in the MMF and is 0.30 in CAM5, which indicates that the response in LWP to a given CCN perturbation in the MMF is about one-third of that in CAM5.
The smaller increase in LWP in the MMF is also caused, to a lesser extent, by a smaller relative increase in $\mathrm{CCN}$ concentrations in the MMF from PI to PD, as shown in Fig. 16c. The relative changes in $\mathrm{CCN}$ concentrations from PI to PD in CAM5 are about $35 \%$ larger than that in the MMF. This is consistent with Figs. 9 and 14, which show that changes in both CCN concentrations and LWP are weaker in the MMF. The smaller relative increases in $\mathrm{CCN}$ concentrations in the MMF can be partly explained by the changes in aerosol lifetimes between the PD and PI simulations (Table 2). The lifetime of sulfate aerosol has little change from the PI to PD simulations in the MMF, but increases by $12 \%$ in CAM5. The lifetime of BC decreases by $7 \%$ from the PI to PD simulations in the MMF, while it increases by $9 \%$ in CAM5. The large increase in sulfate and BC lifetimes in CAM5 from the PI to PD simulations can be explained in part by the positive feedback in aerosol indirect effects due to cloud lifetime effects from aerosols (more aerosols lead to longer cloud lifetime and therefore less wet scavenging, which in turn increases $\mathrm{CCN}$ concentrations). This positive feedback 

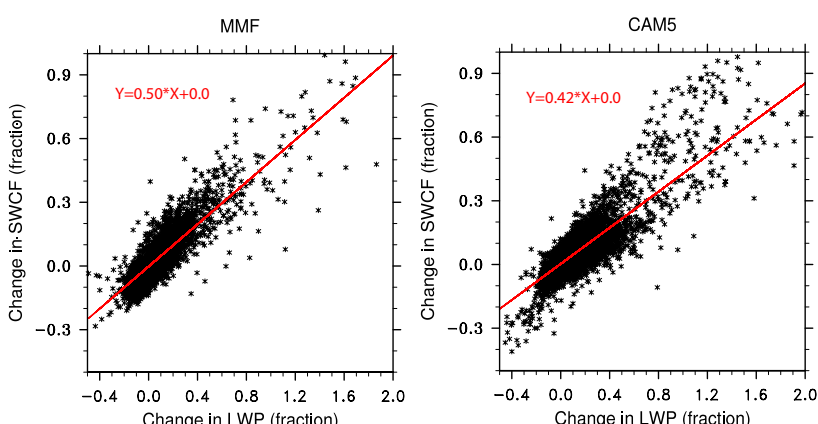

Fig. 15. Scatter plots and regressions of the relative changes [(PD$\mathrm{PI} / \mathrm{PI}]$ in annual-mean shortwave cloud forcing (SWCF) versus the relative changes in annual-mean liquid water path (LWP) in both the MMF (left panel) and CAM5 (right panel) from PI to PD. Annual mean model data are sampled on each GCM grid column from $60^{\circ} \mathrm{S}$ to $60^{\circ} \mathrm{N}$. LWP in CAM5 includes contributions from both largescale and convective clouds. Red lines and equations are from the linear regression.

induced by cloud lifetime effects from aerosols is stronger in CAM5 than in the MMF, partly due to the larger increase in LWP in CAM5. The smaller relative increase in CCN concentrations in the MMF is also partly caused by the smaller relative increase in sulfate sources in the MMF (Table 2). The sulfate source increases by $130 \%$ from PI to PD in the MMF, while it increases by $178 \%$ in CAM5. This is partly caused by the changes in the lifetime of $\mathrm{SO}_{2}$, which decreases by $14 \%$ from PI to PD in the MMF, while increases by $20 \%$ in CAM5. The differences in changes in sulfate source and $\mathrm{SO}_{2}$ lifetime from PI to PD result from differences in the treatment of wet removal of $\mathrm{SO}_{2}$ (less efficient wet removal of $\mathrm{SO}_{2}$ in the MMF), differences in the magnitude of cloud lifetime effects from aerosols (weaker cloud lifetime effects in the MMF) and differences in the treatment of aqueous chemistry (a fixed $\mathrm{pH}$ value of 4.5 in the MMF versus a $\mathrm{SO}_{4}$-dependent $\mathrm{pH}$ value in CAM5) (Wang et al., 2011; Liu et al., 2011).

The higher sulfate burdens in the MMF versus CAM5 do not appear to contribute significantly to different LWP response to a given $\mathrm{CCN}$ perturbation and the stronger indirect effect in CAM5. In the reduced-SO $\mathrm{S}_{2}$-wet-removal sensitivity test (see the discussion in Sect. 3.2 about the sensitivity test and the differences in the treatment of $\mathrm{SO}_{2}$ wet removal between the MMF and CAM5), reducing $\mathrm{SO}_{2}$ wet removal has little effect on simulated LWP response to a given CCN perturbation and slightly increases aerosol indirect forcing in CAM5, even though it increases the PD and PI sulfate burdens by $28 \%$ and $40 \%$, respectively.

To further examine how clouds with different LWP respond differently to anthropogenic aerosols, Fig. 17 shows the probability density function (PDF) of in-cloud LWP over the globe in the PD simulations and the relative changes in this PDF from the PI to PD simulations in both the MMF and CAM5. Model output (34 months data for the MMF and $4 \mathrm{yr}$ data for CAM5) are sampled daily at 01:30 pm local time. The in-cloud LWP in CAM5 is derived from the grid-mean LWP and the liquid cloud cover calculated based on the same maximum/random cloud overlap assumption as used in the radiative transfer calculation in CAM5. The PDFs of LWP calculated from in-cloud LWP at each GCM column in both the MMF and CAM5 (Fig. 17c and d) are weighted by cloud cover. In-cloud LWP in CAM5 includes a contribution from stratiform clouds only, while in-cloud LWP in the MMF includes contributions from both stratiform and convective clouds. The PDFs of LWP in PD show that the frequency of occurrence of LWP decreases with increasing LWP and that clouds with LWP larger than $200 \mathrm{~g} \mathrm{~m}^{-2}$ occur more often in the MMF than in CAM5 (Fig. 17a).

The relative changes in the PDF of LWP (green lines in Fig. 17b-d) show that cloud fraction of thin clouds decreases and that cloud fraction of thick clouds increases in both the MMF and CAM5 from the PI to PD simulations (relative changes in the frequency of occurrence at a given LWP bin is equivalent to relative changes in cloud fraction at that given LWP bin). It is also evident in Fig. 17b-d that increases in cloud fraction in thick clouds accelerate with increasing LWP bins. For example, the decreases in cloud fraction can reach as high as $2 \%$ for the smallest LWP bins, while the increase in cloud fraction can be larger than $10 \%$ for clouds with LWP larger than $1000 \mathrm{~g} \mathrm{~m}^{-2}$ in the MMF. The different responses of thin and thick cloud LWP to anthropogenic aerosol perturbations can be explained in part by cloud lifetime effects from aerosols. Thick clouds are more likely to precipitate and therefore their LWP are more susceptible to anthropogenic aerosol perturbations. The accelerating increase in cloud fraction for thick clouds with increasing LWP may partly result from the autoconversion scheme used in the models, which is based on Khairoutdinov and Kogan (2000). The autoconversion rate in the Khairoutdinov and Kogan scheme has a strong dependence on liquid water content $\left(q_{c}^{2.47}\right)$, which leads to a strong dependence of the relative autoconversion rate (the autoconversion rate divided by liquid water content) on liquid water content $\left(q_{c}^{1.47}\right)$ and therefore larger relative increases in cloud fraction for clouds with larger LWP. On the other hand, thin clouds are less likely precipitating and their LWPs are therefore less susceptible to anthropogenic aerosol perturbations. Other factors, such as semi-direct effects and dynamical feedbacks (e.g., entrainment drying, Ackerman et al., 2004) can even lead to a decrease in cloud fraction for these thin clouds.

Figure 17 also further demonstrated that the response in LWP to anthropogenic aerosol perturbation is much larger in CAM5 than in the MMF, consistent with Fig. 16. In CAM5, cloud fraction increases for clouds with in-cloud LWP larger than $50 \mathrm{~g} \mathrm{~m}^{-2}$ and increases by more than $20 \%$ for clouds with LWP larger than $200 \mathrm{~g} \mathrm{~m}^{-2}$, and more than $50 \%$ for clouds with LWP larger than $400 \mathrm{~g} \mathrm{~m}^{-2}$, which are much larger than those in the MMF. The larger response in LWP 

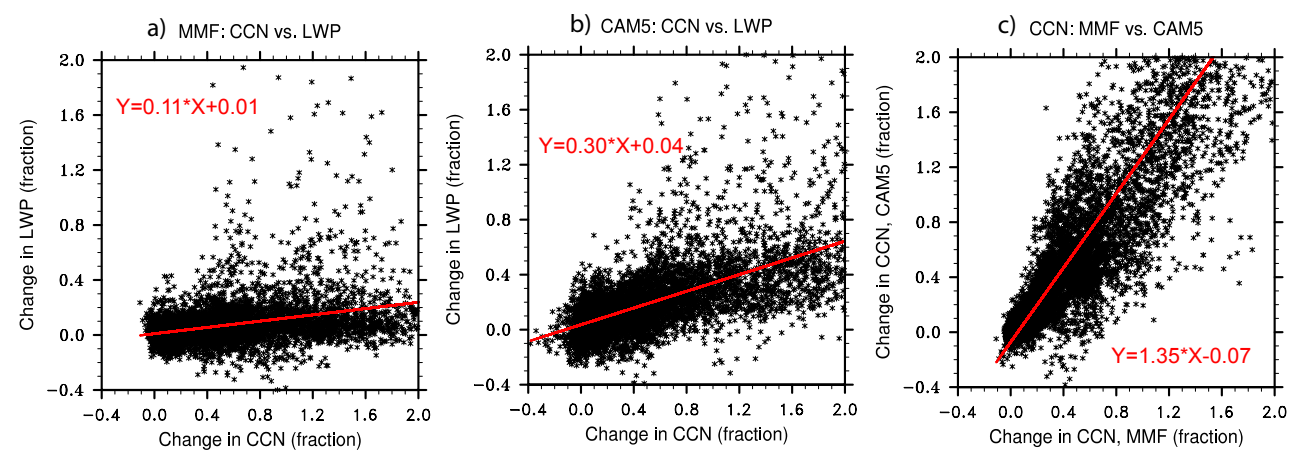

Fig. 16. Scatter plots and regressions of (a) the relative changes [(PD-PI)/PI] in annual-mean liquid water path (LWP) versus the relative changes in annual-mean CCN concentrations in the MMF model, (b) like (a) but in the CAM5 model; (c) the relative changes in annualmean CCN concentrations (at $0.1 \%$ supersaturation) in CAM5 versus that in the MMF. LWP in CAM5 only includes the contribution from large-scale clouds. Annual mean data are sampled on each GCM grid column from $60^{\circ} \mathrm{S}$ to $60^{\circ} \mathrm{N}$. CCN concentrations are averaged over the lowest 8 model levels (surface to about $800 \mathrm{hPa}$ ). Red lines and equations are from the linear regression.

in CAM5 can also be seen in the changes in the cumulative PDF of LWP (blue lines in Fig. 17b-d) and the cumulative LWP (red lines in Fig. 17b-d and see the caption in Fig. 17 for the definition), and are consistent with the gridmean LWP changes shown in Fig. 14. Changes in grid-mean LWP come from both changes in cloud fraction (the cumulative PDF) and in in-cloud LWP (the cumulative LWP). Figure 17 shows that the $3.9 \%$ increase in grid-mean LWP in the MMF is mainly from the changes in in-cloud LWP (the cumulative LWP), while the $15.6 \%$ increase in LWP from stratiform clouds in CAM5 is from about $5 \%$ increase in cloud fraction (the cumulative PDF), and $10 \%$ increase in in-cloud LWP (the cumulative LWP).

It is clear from previous discussions that the response in LWP to anthropogenic perturbation in the MMF is quite different from that in CAM5. The response in LWP to a given $\mathrm{CCN}$ perturbation is only about one-third that in CAM5. The MMF also produces more regions with negative response in LWP to anthropogenic aerosols than CAM5 (compare Figs. 9 and 14). Negative changes in cloud fraction in the MMF extend to thicker clouds than in CAM5 (Fig. 17). These differences may point to the challenges in simulating cloud lifetime effects from aerosols in conventional GCMs. In most conventional GCMs, increases in cloud droplet number concentration due to the addition of anthropogenic aerosol particles lead to less efficient coalescence and collection among cloud droplets, which results in larger LWPs and longer cloud lifetimes (Albrecht, 1989). However, ship track studies show that anthropogenic aerosols can lead to less liquid water (Platnick et al., 2000; Coakley and Walsh, 2002), and satellite studies show both decreases and increases in LWP with increasing aerosols (Kaufman et al., 2005; Matsui et al., 2006). CRM studies have suggested that LWP can either increase or decrease with increasing aerosols, depending on the meteorological conditions (Ackerman et al., 2004; Jiang et al., 2006; Guo et al., 2007; Xue et al., 2008; Small et al., 2009). The decreasing LWP with increasing aerosols can be attributed to enhanced entrainment of dry air or enhanced evaporation of the more numerous smaller cloud droplets in polluted clouds. Stevens and Feingold (2009) further argued that the aerosol-cloud interactions work in a buffered system, and cloud lifetime effects from aerosols as hypothesized in the system in isolation may be canceled or compensated for by opposing changes when the system is viewed as a whole. Most conventional GCMs implemented cloud lifetime effects from aerosols through their stratiform cloud parameterization and are not able to account for the sophisticated balance between different factors, and hence may overestimate cloud lifetime effects from aerosols. Compared with CAM5, the smaller increase in LWP in the MMF model is more consistent with the observations and with CRM studies.

\subsubsection{Comparison with other studies}

The smaller increase in LWP due to anthropogenic aerosol in the MMF model than in CAM5 is consistent with Lohmann (2008), who showed a slightly smaller response in LWP in a version of the ECHAM including aerosol effects on convective clouds using cumulus parameterization (8.2\%) compared to a version of the ECHAM without aerosol effects on convective clouds $(9.7 \%)$ though conventional cloud parameterizations are used for both stratiform and convective clouds. In Lohmann (2008), the total aerosol effect decreased slightly from $-1.9 \mathrm{~W} \mathrm{~m}^{-2}$ without aerosol effects on convective clouds to $-1.7 \mathrm{~W} \mathrm{~m}^{-2}$ with aerosol effects on convective clouds. Our results are also consistent with the GISS model results in Menon and Rotstayn (2006), which simulated a smaller increase in LWP due to anthropogenic aerosols when aerosol effects on convective clouds were included. In contrast, the CSIRO model in Menon and Rotstayn (2006) simulated a larger increase in LWP when aerosol effects on convective clouds were included. Menon and Rotstayn (2006) 
a) PDF in the PD

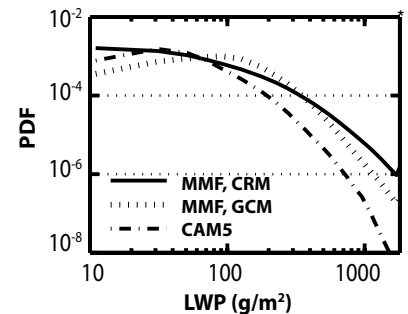

c) MMF, GCM

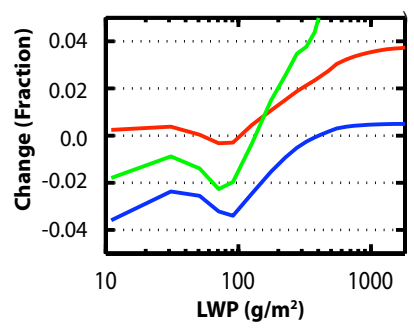

Fig. 17. (a) The PDFs of LWP in the PD simulations in the MMF and CAM5 (solid line is from the in-cloud LWP in CRM columns in the MMF; dotted line is from the in-cloud LWP in GCM columns in the MMF; and dash-dot line is from in-cloud LWP in GCM columns in CAM5); (b-d) relative changes in the PDF of LWP from PI to PD [(PD-PI)/PI] in both the MMF and CAM5. The PDF of LWP are calculated from (b) the in-cloud LWP in CRM columns in MMF, (c) in-cloud LWP in GCM columns in MMF, and (d) in-cloud LWP in GCM columns in CAM5. Green lines are for the relative changes in the PDF of LWP (scaled by a factor of 0.5); blue lines are for the relative changes in the cumulative PDF of LWP; and red lines are for the relative changes in the cumulative LWP. The cumulative PDF of LWP (cumu_PDF) at a given LWP bin $\left(\mathrm{LWP}^{\prime}\right)$ is: cumu_PDF $=\int_{\mathrm{LWP}_{\min }}^{\mathrm{LWP}^{\prime}} \operatorname{PDF}(\mathrm{LWP}) \mathrm{dLWP}$, where PDF(LWP) is the PDF of LWP, and mWP $_{\text {min }}$ is the smallest LWP bin. The cumulative LWP (cumu_LWP) at a given LWP bin $\left(\mathrm{LWP}^{\prime}\right)$ is the averaged incloud LWP from the smallest LWP bin $\left(\mathrm{LWP}_{\min }\right)$ to the given LWP bin: cumu_LWP $=\frac{1}{\text { cumu_PDF }} \int_{L W P_{\min }}^{L W^{\prime}} \operatorname{PDF}(\mathrm{LWP})^{*}$ LWPdLWP.

attributed the different responses in the CSIRO and GISS models to the different treatment of detrained condensate in their cumulus parameterizations, which included different treatments on how to partition convective condensate into precipitation and detrained condensate, and on how to treat detrained cloud condensate (instantly evaporated in CSIRO, and directly added as anvil clouds in GISS). It is not clear in Menon and Rotstayn (2006) how these differences lead to different responses in LWP to anthropogenic aerosols in the two models.

The estimated shortwave cloudy-sky forcing, calculated from subtracting aerosol effects in the clear sky weighted by the clear-sky fraction from the total shortwave forcing, is $-1.07 \mathrm{~W} \mathrm{~m}^{-2}$, which is at the low end of the estimates of global aerosol-climate models included in a recent AeroCom indirect effect model intercomparison study (Quaas et al., 2009). The estimated shortwave cloudy-sky forcing in Quaas et al. (2009) ranged from -0.27 to $-1.87 \mathrm{~W} \mathrm{~m}^{-2}$ with a mean value of $-1.15 \mathrm{~W} \mathrm{~m}^{-2}$ though none of the participated AeroCom models included aerosol indirect effects on convective clouds. The AeroCom models that produced small shortwave cloudy-sky forcing typically set a larger lower limit for simulated droplet number concentrations ranging from 20 to $40 \mathrm{~cm}^{-3}$. It has been shown in several previous studies (Ghan et al., 2001; Hoose et al., 2009; Wang and Penner, 2009) that the larger lower limits usually lead to smaller aerosol indirect effects. The CRM in the MMF model does not include any lower limit on simulated cloud droplet number concentrations, the same as CAM5 and several other models in Quaas et al. (2009) that generally produced larger shortwave cloudy-sky forcing.

The AeroCom models that produced low shortwave cloudsky forcing also typically had a weak dependence of autoconversion rate on cloud droplet number concentrations. For example, the smallest forcing in the AeroCom models $\left(-0.27 \mathrm{~W} \mathrm{~m}^{-2}\right)$ is from a model that has an autoconversion scheme independent of cloud droplet number concentrations. The AeroCom models that used the same Khairoutdinov and Kogan (2000) scheme as in the MMF and CAM5, which gives the strongest dependence of autoconversion rate on cloud droplet number concentrations $\left(N_{d}^{-1.79}\right)$ among the AeroCom models, generally produced large changes in shortwave cloud forcing. It must be noted that the Khairoutdinov and Kogan scheme is applied at each CRM grid point with a grid spacing of 4 kilometers in the MMF model, while it is applied at each GCM grid point with a grid spacing of several hundred kilometers in CAM5 and other conventional GCMs included in the AeroCom study. To take account of the strongly non-linear dependence of autoconversion rate on subgrid cloud liquid water, most conventional GCMs either derive the autoconversion rate based on an assumed probability distribution of subgrid cloud liquid water or simply tune the autoconversion rate to produce reasonable results (Pincus and Klein, 2000; Rotstayn, 2000; Larson et al., 2001; Morrison and Gettelman, 2008). Subgrid variations in cloud droplet number concentrations are typically neglected in these GCMs. For example, CAM5 assumes a gamma distribution of subgrid cloud liquid water content with a relative variance of 2 and neglects the subgrid variation in cloud droplet number concentrations, which results in a scaling factor of about 2 applied to the autoconversion rate calculated based on the GCM-scale in-cloud liquid water content and cloud droplet number concentration (Morrison and Gettelman, 2008). Neglecting the subgrid variation in cloud droplet number concentrations may bias the autoconversion rate, since cloud droplet number concentrations may correlate with cloud water content on the subgrid scale (e.g., larger cloud water may be well associated with larger droplet number concentrations). It is not clear how the differences in scale may play a role on the differences in aerosol indirect effects between the MMF model and conventional GCMs. 
Aerosol effects in the clear-sky (assuming entirely clear grid boxes) in Quaas et al. (2009) range from -0.17 to $-1.76 \mathrm{~W} \mathrm{~m}^{-2}$, with a mean value of $-0.68 \mathrm{~W} \mathrm{~m}^{-2}$. Our estimated aerosol effect in the clear-sky (assuming entirely clear grid boxes) is $-0.54 \mathrm{~W} \mathrm{~m}^{-2}$, and is in the range of the AeroCom model estimates in Quaas et al. (2009). The clearsky aerosol forcing efficiency (forcing per unit anthropogenic AOD) is $-22.5 \mathrm{~W} \mathrm{~m}^{-2}$ per unit anthropogenic AOD, which is in the range of the estimates in the AeroCom study (from -2.78 to -30.71 ). The clear-sky aerosol forcing efficiency in this study is also close to the results in an early AeroCom intercomparison study of Schulz et al. (2006) that focused on aerosol direct effects only, which range from -10 to $-33 \mathrm{~W} \mathrm{~m}^{-2}$ per unit anthropogenic AOD, with a mean of $-23 \mathrm{~W} \mathrm{~m}^{-2}$ per unit anthropogenic AOD.

Our estimated total aerosol effect on the shortwave radiative fluxes at the top of the atmosphere is $-1.31 \mathrm{~W} \mathrm{~m}^{-2}$, which falls well within the model results of Quaas et al. (2009) that range from -0.50 to $-2.56 \mathrm{~W} \mathrm{~m}^{-2}$, with a mean value of $-1.57 \mathrm{~W} \mathrm{~m}^{-2}$. The estimated total aerosol effect on the net radiative fluxes at the top of the atmosphere is $-1.05 \mathrm{~W} \mathrm{~m}^{-2}$, which is close to the inverse estimate of $-1.1 \pm 0.4 \mathrm{~W} \mathrm{~m}^{-2}(1 \sigma)$ based on the examination of the Earth's energy balance in Murphy et al. (2009).

\section{Summary and further discussion}

In this study, we have evaluated model fields in a multiscale aerosol-climate model and examined aerosol effects on clouds and climate. The PNNL-MMF multi-scale aerosolclimate model is an extension of the Colorado State University (CSU) multi-scale modeling framework (MMF) model (Khairoutdinov et al., 2005, 2008; Tao et al., 2009) and consists of three components (Wang et al., 2011). The general circulation model (GCM) component is NCAR CAM5 and includes a modal aerosol treatment that uses several log-normal modes to represent aerosol size distributions. The second component is a cloud resolving model (CRM), which has a two-moment microphysics scheme and predicts both hydrometeor mass and number mixing ratios. The CRM is embedded in each GCM grid column and replaces the conventional parameterizations of convective and stratiform clouds, which permits the explicit simulation of convective clouds. The third component of this multi-scale aerosol-climate model is the Explicit-Cloud-ParameterizedPollutant approach, which uses cloud statistics diagnosed from the CRM component of the MMF model to drive the aerosol and trace gas processing by clouds. This multiscale aerosol-climate model allows us to simulate aerosolcloud interactions in both stratiform and convective clouds in a more physically-based manner than most conventional GCMs. Wang et al. (2011) showed that this model simulates aerosol fields in reasonable agreement with observations.
Simulated model fields, including liquid water path (LWP), ice water path, cloud fraction, shortwave and longwave cloud forcing, precipitation and water vapor are in reasonable agreement with observations. However, the model underestimates cloud fraction, especially for low clouds, and overestimates precipitation rate over the tropical ocean and underestimates precipitation over the mid-latitudes. The model performs quantitatively similarly to the previous version of the MMF model in terms of simulated cloud fraction and precipitation, and the two-moment cloud microphysics coupled with a modal aerosol treatment provides little help in reducing biases in these fields. Simulated cloudtop droplet number concentrations are in reasonable agreement with satellite observations, with larger droplet number concentrations over land than over ocean, and over the $\mathrm{NH}$ than over the SH. A large fraction of total ice water mass is from snow, and including the radiative effects of snow significantly increases both shortwave and longwave cloud forcing. Simulated sulfate, BC, POM and SOA burdens are larger in the MMF than in CAM5, which can be explained in part by the smaller wet removal rate in the MMF. Simulated aerosol size distributions in the marine boundary layer in the MMF are similar with those in CAM5, and agree slightly better with observations. $\mathrm{BC}$ concentrations in the polar regions in the MMF are much higher than that in CAM5 and agree better with observations in terms of both magnitude and seasonal cycle.

The simulated change of $-0.77 \mathrm{~W} \mathrm{~m}^{-2}$ in shortwave cloud forcing in the MMF is less than half of that in CAM5 $\left(-1.79 \mathrm{~W} \mathrm{~m}^{-2}\right)$, though decreases in simulated cloud-top droplet effective radius from anthropogenic aerosols are slightly larger in the MMF than in CAM5 $(-0.53 \mu \mathrm{m}$ vs. $-0.45 \mu \mathrm{m})$. The simulated change in cloudy-sky forcing in the MMF is also at the low end of the estimates of global climate models included in a recent AeroCom aerosol indirect effect intercomparison study (Quaas et al., 2009). The simulated total aerosol effects on the net radiative flux is $-1.05 \mathrm{~W} \mathrm{~m}^{-2}$, which is close to the inverse estimate of $-1.1 \pm 0.4 \mathrm{~W} \mathrm{~m}^{-2}(1 \sigma)$ based on the examination of the Earth's energy balance in Murphy et al. (2009).

The smaller forcing in the MMF model is attributed to the much smaller increase in LWP from anthropogenic aerosols (3.9\% in the MMF, compared with $15.6 \%$ increase in LWP in stratiform clouds in CAM5). The much smaller increase in LWP in the MMF can be explained by the much smaller response in LWP to a given change in CCN concentrations in the MMF, which is only about one-third of that in CAM5, and, to a lesser extent, by the smaller relative increase in $\mathrm{CCN}$ concentrations from the PI to the PD simulations in the MMF, which is about $74 \%$ of that in CAM5 (Fig. 16). The smaller relative increase in $\mathrm{CCN}$ concentrations in the MMF is caused in part by the smaller positive feedback between aerosols and clouds due to cloud lifetime effects from aerosols. The higher sulfate burden in the MMF versus CAM5 does not appear to contribute significantly to the 
Table 5. Changes in global annual mean cloud and radiative parameters between the PI and PD simulations (PD-PI) in both the MMF and CAM5: aerosol optical depth (AOD), cloud-top droplet number concentrations (CDNC), cloud-top droplet effective radius (CDR), liquid water path (LWP), shortwave (SWCF) and longwave (LWCF) cloud forcing, clear-sky (FSNTC) and whole-sky (FSNT) shortwave radiative fluxes at the top of the atmosphere, and whole-sky longwave radiative flux (FLNT) at the top of the atmosphere. For LWP from CAM5, the change in LWP from large-scale clouds is in parenthesis.

\begin{tabular}{lrrrrrrrrr}
\hline & $\begin{array}{r}\Delta \mathrm{AOD} \\
(-)\end{array}$ & $\begin{array}{r}\Delta \mathrm{CDNC} \\
\left(\mathrm{cm}^{-3}\right)\end{array}$ & $\begin{array}{r}\Delta \mathrm{CDR} \\
(\mu \mathrm{m})\end{array}$ & $\begin{array}{r}\Delta \mathrm{LWP} \\
\left(\mathrm{g} \mathrm{m}^{-2}\right)\end{array}$ & $\begin{array}{r}\Delta \mathrm{SWCF} \\
\left(\mathrm{W} \mathrm{m}^{-2}\right)\end{array}$ & $\begin{array}{r}\Delta \mathrm{LWCF} \\
\left(\mathrm{W} \mathrm{m}^{-2}\right)\end{array}$ & $\begin{array}{r}\Delta \mathrm{FSNTC} \\
\left(\mathrm{W} \mathrm{m}^{-2}\right)\end{array}$ & $\begin{array}{r}\Delta \mathrm{FSNT} \\
\left(\mathrm{W} \mathrm{m}^{-2}\right)\end{array}$ & $\begin{array}{r}\Delta \text { FLNT } \\
\left(\mathrm{W} \mathrm{m}^{-2}\right)\end{array}$ \\
\hline MMF & 0.024 & 24.4 & -0.53 & 2.11 & -0.77 & -0.06 & -0.54 & -1.31 & 0.26 \\
CAM5 & 0.019 & 29.6 & -0.45 & $\begin{array}{r}3.93 \\
(4.04)\end{array}$ & -1.79 & 0.37 & -0.45 & -2.25 & 0.59 \\
& & & & & & & & \\
\hline
\end{tabular}

MMF/CAM5 indirect forcing differences. The smaller response in LWP may indicate that aerosol indirect effects simulated in conventional global climate models are overestimated.

Cloud-top droplet number concentration (CDNC) increases with increasing AOD in the MMF model, which is consistent with satellite data and other model studies, though the slope between $\ln (\mathrm{CDNC})$ and $\ln (\mathrm{AOD})$ in the MMF is overestimated compared with satellite data (Fig. 11). Simulated cloud fraction and AOD are negatively correlated in the MMF, similar to CAM5, but opposite to many other conventional aerosol-climate models, although cloud fraction and AI are slightly positively correlated in the MMF model. The negative correlation may suggest stronger scavenging effects of clouds and less swelling of aerosols near clouds in the MMF and CAM5.

Cloud LWP increases with increasing AOD over land in the MMF model, with a larger slope between $\ln (\mathrm{LWP})$ and $\ln (\mathrm{AOD})$ in the MMF than in CAM5 and satellite data (Fig. 11). In contrast, cloud LWP decreases with increasing AOD over ocean, which is opposite to CAM5 and many other aerosol-climate models. Both positive and negative correlation between LWP and AOD have been observed, and simulated in CRM models. We note that the differences in slopes between $\ln (\mathrm{LWP})$ and $\ln (\mathrm{AOD})$ in the MMF and CAM5 (Fig. 11) are not consistent with the differences in aerosol indirect forcing and the LWP response to a given CCN perturbation in the MMF and CAM5 (Fig. 16a-b). The slopes between $\ln (\mathrm{LWP})$ and $\ln (\mathrm{AI})$ show large differences over land and ocean (Fig. 11), while the slopes between the relative changes in LWP and the relative changes in $\mathrm{CCN}$ from PI to PD are similar over both land and ocean (not shown), close to the values shown in Fig. 16. While the slopes between $\ln (\mathrm{LWP})$ and $\ln (\mathrm{AI})$ over land are larger in the MMF than in CAM5, the slopes between the relative change in LWP and the relative changes in CCN from PI to PD over land are much smaller in the MMF than in CAM5 (not shown), similar to the differences shown in Fig. 16a-b. This may point to the limitations of the approach applied in Fig. 11. As LWP and aerosol burden are coupled by many non-microphysical factors (e.g., swelling effects of aerosols by clouds, and large-scale convergence), it is difficult to separate the microphysical factors from the non-microphysical factors in the slopes of $\ln (\mathrm{LWP})$ and $\ln (\mathrm{AI})$ in PD, which makes it not a good indicator for cloud lifetime effects from aerosols.

We note that a short integration time (34 months) is used for the MMF model in this study. The MMF model is an expensive model, and we are constrained by the limited computing resources to have longer simulations for this study. Since the simulations are driven by fixed climatological sea surface temperature and sea ice, the interannual natural variability of global means is quite small in these simulations and we do not expect our results to be sensitive to the short integration time. This is especially true for the annual mean results, which are the basis for most of the major conclusions presented here. For example, the slopes between the relative change in LWP and the relative change in $\mathrm{CCN}$ in CAM5 (Fig. 16b) vary little when we varied the averaging time from 24 months to 48 months (the slopes are 0.306 for the 24-month average, 0.290 for 34-month average, 0.286 for 36-month average, and 0.304 for the 48 -month averages).

Further improvements in the representation of ice nucleation and low clouds are needed. In this study, ice nucleation in the MMF model is not directly related to aerosol particles, while in CAM5, aerosol effects on ice clouds produce a warming longwave effect (Table 5). Including aerosol effects on ice clouds in the MMF therefore may lead to an even smaller total aerosol effect. The CRM in this study also lacks a high-order turbulence scheme, and including such a scheme could improve the simulation of lower level clouds in the MMF model. These limitations will be addressed in future studies.

Acknowledgements. This work is supported by the NASA Interdisciplinary Science Program under grant NNX07AI56G and by the US Department of Energy, Office of Science, Atmospheric System Research program and Scientific Discovery through Advanced Computing (SciDAC) program. The Pacific Northwest National Laboratory (PNNL) is operated for the DOE by Battelle Memorial Institute under contract DE-AC06-76RLO 1830. We thank Duli Chand for his internal review and constructive comments. H. M. was supported by the NOAA grant NA08OAR4310543, 
US DOE ARM DE-FG02-08ER64574, and the NSF Science and Technology Center For Multiscale Modeling of Atmospheric Processes (CMMAP), managed by Colorado State University under cooperative agreement ATM-0425247. We are also grateful to Johannes Quaas for providing scripts to examine the aerosol/cloud relationships in models in Fig. 6 and for satellite data used in Fig. 11. Three anonymous reviewers provided constructive comments, which help improve the manuscript.

Edited by: C. Hoose

\section{References}

Abdul-Razzak, H. and Ghan, S. J.: A parameterization of aerosol activation 2. Multiple aerosol types, J. Geophys. Res., 105, 6837-6844, 2000.

Ackerman, A. S., Kirkpatrick, M. P., Stevens, D. E., and Toon, O. B.: The impact of humidity above stratiform clouds on indirect aerosol climate forcing, Nature, 432, 1014-1017, doi:10.1038/Nature03174, 2004.

Albrecht, B. A.: Aerosols, Cloud Microphysics, and Fractional Cloudiness, Science, 245, 1227-1230, 1989.

Arimoto, R., Duce, R. A., Savoie, D. L., Prospero, J. M., Talbot, R., Cullen, J. D., Tomza, U., Lewis, N. F., and Jay, B. J.: Relationships among aerosol constituents from Asia and the North Pacific during PEM-West A, J. Geophys. Res., 101, 2011-2023, 1996.

Austin, R. T., Heymsfield, A. J., and Stephens, G. L.: Retrieval of ice cloud microphysical parameters using the CloudSat millimeter-wave radar and temperature, J. Geophys. Res., 114, D00A23, doi:10.1029/2008jd010049, 2009.

Bigg, E. K.: The Supercooling of Water, P. Phys. Soc. Lond. B, 66, 688-694, 1953.

Bodhaine, B. A.: Aerosol Absorption-Measurements at Barrow, Mauna-Loa and the South-Pole, J. Geophys. Res., 100, 89678975, 1995.

Coakley, J. A. and Walsh, C. D.: Limits to the aerosol indirect radiative effect derived from observations of ship tracks, J. Atmos. Sci., 59, 668-680, 2002.

Cooper, W. A.: Ice Initiation in natural clouds, in: Precipitation Enhancement - A Scientific Challenge, Meteor. Monogr., Amer. Meteor. Soc., Boston, United States, 29-32, 1986.

Del Genio, A. D., Kovari, W., Yao, M. S., and Jonas, J.: Cumulus microphysics and climate sensitivity, J. Climate, 18, 2376-2387, 2005.

Dentener, F., Kinne, S., Bond, T., Boucher, O., Cofala, J., Generoso, S., Ginoux, P., Gong, S., Hoelzemann, J. J., Ito, A., Marelli, L., Penner, J. E., Putaud, J.-P., Textor, C., Schulz, M., van der Werf, G. R., and Wilson, J.: Emissions of primary aerosol and precursor gases in the years 2000 and 1750 prescribed data-sets for AeroCom, Atmos. Chem. Phys., 6, 4321-4344, doi:10.5194/acp6-4321-2006, 2006.

Emanuel, K. A. and Zivkovic-Rothman, M.: Development and evaluation of a convection scheme for use in climate models, J. Atmos. Sci., 56, 1766-1782, 1999.

Ferraro, R. R., Weng, F. Z., Grody, N. C., and Basist, A.: An eightyear (1987-1994) time series of rainfall, clouds, water vapor, snow cover, and sea ice derived from SSM/I measurements, Bull. Amer. Meteor. Soc., 77, 891-905, 1996.
Forster, P., Ramaswamy, V., Artaxo, P., Berntsen, T., Betts, R., Fahey, D. W., Haywood, J., Lean, J., Lowe, D. C., Myhre, G., Nganga, J., Prinn, R., Raga, G., Schulz, M., and Dorland, R. V.: Changes in Atmospheric Constituents and in Radiative Forcing, in: Climate Change 2007: The Physical Science Basis. Contribution of Working Group I to the Fourth Assessment Report of the Intergovernmental Panel on Climate Change, edited by: Solomon, S., Qin, D., Manning, M., Chen, Z., Marquis, M., Averyt, K. B., Tignor, M., and Miller, H. L., Cambridge University Press, Cambridge, United Kingdom and New York, NY, USA, 2007.

Gettelman, A., Liu, X., Ghan, S. J., Morrison, H., Park, S., Conley, A. J., Klein, S. A., Boyle, J., Mitchell, D. L., and Li, J. L. F.: Global simulations of ice nucleation and ice supersaturation with an improved cloud scheme in the Community Atmosphere Model, J. Geophys. Res., 115, D18216, doi:10.1029/2009jd013797, 2010.

Ghan, S. J., Easter, R. C., Chapman, E. G., Abdul-Razzak, H., Zhang, Y., Leung, L. R., Laulainen, N. S., Saylor, R. D., and Zaveri, R. A.: A physically based estimate of radiative forcing by anthropogenic sulfate aerosol, J. Geophys. Res., 106, 52795293, 2001.

Ghan, S. J. and Zaveri, R. A.: Parameterization of optical properties for hydrated internally mixed aerosol, J. Geophys. Res., 112, D10201, doi:10.1029/2006jd007927, 2007.

Greenwald, T. J., Stephens, G. L., Vonderhaar, T. H., and Jackson, D. L.: A physical retrieval of cloud liquid water over the global oceans using special sensor microwave imager (SSM/I) observations, J. Geophys. Res., 98, 18471-18488, 1993.

Guo, H., Penner, J. E., Herzog, M., and Pawlowska, H.: Examination of the aerosol indirect effect under contrasting environments during the ACE-2 experiment, Atmos. Chem. Phys., 7, 535-548, doi:10.5194/acp-7-535-2007, 2007.

Gustafson, W. I., Berg, L. K., Easter, R. C., and Ghan, S. J.: The Explicit-Cloud Parameterized-Pollutant hybrid approach for aerosol-cloud interactions in multiscale modeling framework models: tracer transport results, Environ. Res. Lett., 3, 025005, doi:10.1088/1748-9326/3/2/025005, 2008.

Han, Q. Y., Rossow, W. B., and Lacis, A. A.: Near-Global survey of effective droplet radii in liquid water clouds using ISCCP data, J. Climate, 7, 465-497, 1994.

Han, Q. Y., Rossow, W. B., Chou, J., and Welch, R. M.: Global variation of column droplet concentration in low-level clouds, Geophys. Res. Lett., 25, 1419-1422, 1998.

Hansen, J., Sato, M., and Ruedy, R.: Radiative forcing and climate response, J. Geophys. Res., 102, 6831-6864, 1997.

Haywood, J. M., Ramaswamy, V., and Donner, L. J.: A limitedarea-model case study of the effects of sub-grid scale variations in relative humidity and cloud upon the direct radiative forcing of sulfate aerosol, Geophys. Res. Lett., 24, 143-146, 1997.

Heintzenberg, J., Covert, D. C., and Van Dingenen, R.: Size distribution and chemical composition of marine aerosols: a compilation and review, Tellus B, 52, 1104-1122, 2000.

Hoose, C., Kristjansson, J. E., Iversen, T., Kirkevag, A., Seland, O., and Gettelman, A.: Constraining cloud droplet number concentration in GCMs suppresses the aerosol indirect effect, Geophys. Res. Lett., 36, L12807, doi:10.1029/2009g1038568, 2009.

Hopper, J. F., Worthy, D. E. J., Barrie, L. A., and Trivett, N. B. A.: Atmospheric Observations of Aerosol Black Carbon, Carbon- 
Dioxide, and Methane in the High Arctic, Atmos. Environ., 28, 3047-3054, 1994.

Horowitz, L. W., Walters, S., Mauzerall, D. L., Emmons, L. K., Rasch, P. J., Granier, C., Tie, X. X., Lamarque, J. F., Schultz, M. G., Tyndall, G. S., Orlando, J. J., and Brasseur, G. P.: A global simulation of tropospheric ozone and related tracers: Description and evaluation of MOZART, version 2, J. Geophys. Res., 108, 4784, doi:10.1029/2002jd002853, 2003.

Iacono, M. J., Delamere, J. S., Mlawer, E. J., and Clough, S. A.: Evaluation of upper tropospheric water vapor in the NCAR Community Climate Model (CCM3) using modeled and observed HIRS radiances, J. Geophys. Res., 108, 4037, doi:10.1029/2002jd002539, 2003.

Iacono, M. J., Delamere, J. S., Mlawer, E. J., Shephard, M. W., Clough, S. A., and Collins, W. D.: Radiative forcing by long-lived greenhouse gases: Calculations with the AER radiative transfer models, J. Geophys. Res., 113, D13103, doi:10.1029/2008jd009944, 2008.

IPCC: Climate Change 2007: The Physical Science Basis. Contribution of Working Group I to the Fourth Assessment Report of the Intergovernmental Panel on Climate Change, edited by: Solomon, S., Qin, D., Manning, M., Chen, Z., Marquis, M., Averyt, K. B., Tignor, M., and Miller, H. L., Cambridge University Press, 996 pp., 2007.

Jiang, H. L., Xue, H. W., Teller, A., Feingold, G., and Levin, Z.: Aerosol effects on the lifetime of shallow cumulus, Geophys. Res. Lett., 33, L14806, doi:10.1029/2006g1026024, 2006.

Kaufman, Y. J., Koren, I., Remer, L. A., Rosenfeld, D., and Rudich, Y.: The effect of smoke, dust, and pollution aerosol on shallow cloud development over the Atlantic Ocean, Proc. Natl. Acad. Sci. USA, 102, 11207-11212, doi:10.1073/Pnas.0505191102, 2005.

Khairoutdinov, M. and Kogan, Y.: A new cloud physics parameterization in a large-eddy simulation model of marine stratocumulus, Mon. Wea. Rev., 128, 229-243, 2000.

Khairoutdinov, M., Randall, D., and DeMott, C.: Simulations of the atmospheric general circulation using a cloud-resolving model as a superparameterization of physical processes, J. Atmos. Sci., 62, 2136-2154, 2005.

Khairoutdinov, M., DeMott, C., and Randall, D.: Evaluation of the simulated interannual and subseasonal variability in an AMIPStyle simulation using the CSU multiscale modeling framework, J. Climate, 21, 413-431, doi:10.1175/2007jcli1630.1, 2008.

Khairoutdinov, M. F. and Randall, D. A.: A cloud resolving model as a cloud parameterization in the NCAR Community Climate System Model: Preliminary results, Geophys. Res. Lett., 28, 3617-3620, 2001.

Khairoutdinov, M. F. and Randall, D. A.: Cloud resolving modeling of the ARM summer 1997 IOP: Model formulation, results, uncertainties, and sensitivities, J. Atmos. Sci., 60, 607-625, 2003.

Kiehl, J. T. and Trenberth, K. E.: Earth's annual global mean energy budget, Bull. Amer. Meteor. Soc., 78, 197-208, 1997.

Kinne, S., Schulz, M., Textor, C., Guibert, S., Balkanski, Y., Bauer, S. E., Berntsen, T., Berglen, T. F., Boucher, O., Chin, M., Collins, W., Dentener, F., Diehl, T., Easter, R., Feichter, J., Fillmore, D., Ghan, S., Ginoux, P., Gong, S., Grini, A., Hendricks, J. E., Herzog, M., Horowitz, L., Isaksen, L., Iversen, T., Kirkavag, A., Kloster, S., Koch, D., Kristjansson, J. E., Krol, M., Lauer, A., Lamarque, J. F., Lesins, G., Liu, X., Lohmann, U., Montanaro,
V., Myhre, G., Penner, J. E., Pitari, G., Reddy, S., Seland, O., Stier, P., Takemura, T., and Tie, X.: An AeroCom initial assessment - optical properties in aerosol component modules of global models, Atmos. Chem. Phys., 6, 1815-1834, doi:10.5194/acp-61815-2006, 2006.

Lamarque, J. F., Bond, T. C., Eyring, V., Granier, C., Heil, A., Klimont, Z., Lee, D., Liousse, C., Mieville, A., Owen, B., Schultz, M. G., Shindell, D., Smith, S. J., Stehfest, E., Van Aardenne, J., Cooper, O. R., Kainuma, M., Mahowald, N., McConnell, J. R., Naik, V., Riahi, K., and van Vuuren, D. P.: Historical (1850-2000) gridded anthropogenic and biomass burning emissions of reactive gases and aerosols: methodology and application, Atmos. Chem. Phys., 10, 7017-7039, doi:10.5194/Acp10-7017-2010, 2010.

Larson, V. E., Wood, R., Field, P. R., Golaz, J. C., Vonder Haar, T. H., and Cotton, W. R.: Systematic biases in the microphysics and thermodynamics of numerical models that ignore subgrid-scale variability, J. Atmos. Sci., 58, 1117-1128, 2001.

Lawson, R. P., Baker, B., Pilson, B., and Mo, Q. X.: In situ observations of the microphysical properties of wave, cirrus, and anvil clouds, Part II: Cirrus clouds, J. Atmos. Sci., 63, 3186-3203, 2006.

Liu, X. H., Easter, R. C., Ghan, S. J., Zaveri, R., Rasch, P., Shi, X., Lamarque, J.-F., Gettelman, A., Morrison, H., Vitt, F., Conley, A., Park, S., Neale, R., Hannay, C., Ekman, A., Hess, P., Mahowald, N., Collins, W., Iacon, M., Bretherton, C., and Flanner, M.: Toward a Minimal Representation of Aerosol Direct and Indirect Effects, J. Climate, to be submitted, 2011.

Loeb, N. G., Wielicki, B. A., Doelling, D. R., Smith, G. L., Keyes, D. F., Kato, S., Manalo-Smith, N., and Wong, T.: Toward Optimal Closure of the Earth's Top-of-Atmosphere Radiation Budget, J. Climate, 22, 748-766, doi:10.1175/2008jcli2637.1, 2009.

Lohmann, U.: Global anthropogenic aerosol effects on convective clouds in ECHAM5-HAM, Atmos. Chem. Phys., 8, 2115-2131, doi:10.5194/acp-8-2115-2008, 2008.

Lohmann, U., Spichtinger, P., Jess, S., Peter, T., and Smit, H.: Cirrus cloud formation and ice supersaturated regions in a global climate model, Environ. Res. Lett., 3, 045022, doi:10.1088/17489326/3/4/045022, 2008.

Lohmann, U., Rotstayn, L., Storelvmo, T., Jones, A., Menon, S., Quaas, J., Ekman, A. M. L., Koch, D., and Ruedy, R.: Total aerosol effect: radiative forcing or radiative flux perturbation?, Atmos. Chem. Phys., 10, 3235-3246, doi:10.5194/acp-10-32352010, 2010.

Mahowald, N. M., Muhs, D. R., Levis, S., Rasch, P. J., Yoshioka, M., Zender, C. S., and Luo, C.: Change in atmospheric mineral aerosols in response to climate: Last glacial period, preindustrial, modern, and doubled carbon dioxide climates, J. Geophys. Res., 111, D10202, doi:10.1029/2005jd006653, 2006a.

Mahowald, N. M., Yoshioka, M., Collins, W. D., Conley, A. J., Fillmore, D. W., and Coleman, D. B.: Climate response and radiative forcing from mineral aerosols during the last glacial maximum, pre-industrial, current and doubled-carbon dioxide climates, Geophys. Res. Lett., 33, L20705, doi:10.1029/2006g1026126, 2006b.

Marchand, R. and Ackerman, T.: An analysis of cloud cover in multiscale modeling framework global climate model simulations using 4 and $1 \mathrm{~km}$ horizontal grids, J. Geophys. Res., 115, D16207, doi:10.1029/2009jd013423, 2010. 
Martensson, E. M., Nilsson, E. D., de Leeuw, G., Cohen, L. H., and Hansson, H. C.: Laboratory simulations and parameterization of the primary marine aerosol production, J. Geophys. Res., 108, 4297, doi:10.1029/2002jd002263, 2003.

Matsui, T., Masunaga, H., Kreidenweis, S. M., Pielke, R. A., Tao, W. K., Chin, M., and Kaufman, Y. J.: Satellite-based assessment of marine low cloud variability associated with aerosol, atmospheric stability, and the diurnal cycle, J. Geophys. Res., 111, D17204, doi:10.1029/2005jd006097, 2006.

McComiskey, A., Feingold, G., Frisch, A. S., Turner, D. D., Miller, M. A., Chiu, J. C., Min, Q. L., and Ogren, J. A.: An assessment of aerosol-cloud interactions in marine stratus clouds based on surface remote sensing, J. Geophys. Res., 114, D09203, doi:10.1029/2008jd011006, 2009.

Menon, S. and Rotstayn, L.: The radiative influence of aerosol effects on liquid-phase cumulus and stratiform clouds based on sensitivity studies with two climate models, Climate Dyn., 27, 345-356, doi:10.1007/S00382-006-0139-3, 2006.

Mlawer, E. J., Taubman, S. J., Brown, P. D., Iacono, M. J., and Clough, S. A.: Radiative transfer for inhomogeneous atmospheres: RRTM, a validated correlated-k model for the longwave, J. Geophys. Res., 102, 16663-16682, 1997.

Morrison, H., Curry, J. A., and Khvorostyanov, V. I.: A new doublemoment microphysics parameterization for application in cloud and climate models. Part I: Description, J. Atmos. Sci., 62, 16651677, 2005.

Morrison, H. and Pinto, J. O.: Mesoscale modeling of springtime Arctic mixed-phase stratiform clouds using a new two-moment bulk microphysics scheme, J. Atmos. Sci., 62, 3683-3704, 2005.

Morrison, H. and Gettelman, A.: A new two-moment bulk stratiform cloud microphysics scheme in the community atmosphere model, version 3 (CAM3). Part I: Description and numerical tests, J. Climate, 21, 3642-3659, doi:10.1175/2008jcli2105.1, 2008.

Morrison, H., Thompson, G., and Tatarskii, V.: Impact of Cloud Microphysics on the Development of Trailing Stratiform Precipitation in a Simulated Squall Line: Comparison of Oneand Two-Moment Schemes, Mon. Wea. Rev., 137, 991-1007, doi:10.1175/2008mwr2556.1, 2009.

Murphy, D. M., Solomon, S., Portmann, R. W., Rosenlof, K. H., Forster, P. M., and Wong, T.: An observationally based energy balance for the Earth since 1950, J. Geophys. Res., 114, D17107, doi:10.1029/2009jd012105, 2009.

Nakajima, T., Higurashi, A., Kawamoto, K., and Penner, J. E.: A possible correlation between satellite-derived cloud and aerosol microphysical parameters, Geophys. Res. Lett., 28, 1171-1174, 2001.

Pincus, R. and Klein, S. A.: Unresolved spatial variability and microphysical process rates in large-scale models, J. Geophys. Res., 105, 27059-27065, 2000.

Platnick, S., Durkee, P. A., Nielsen, K., Taylor, J. P., Tsay, S. C., King, M. D., Ferek, R. J., Hobbs, P. V., and Rottman, J. W.: The role of background cloud microphysics in the radiative formation of ship tracks, J. Atmos. Sci., 57, 2607-2624, 2000.

Platnick, S., King, M. D., Ackerman, S. A., Menzel, W. P., Baum, B. A., Riedi, J. C., and Frey, R. A.: The MODIS cloud products: Algorithms and examples from Terra, Ieee Trans. Geosci. Remote Sens., 41, 459-473, 2003.

Prospero, J. M., Uematsu, M., and Savoie, D. L.: Mineral aerosol transport to the Pacific Ocean, in: Chemical Oceanography, edited by: Ridley, J. P., Chester, R., and Duce, R. A., Elsevier, New York, 188-218, 1989.

Quaas, J., Boucher, O., and Lohmann, U.: Constraining the total aerosol indirect effect in the LMDZ and ECHAM4 GCMs using MODIS satellite data, Atmos. Chem. Phys., 6, 947-955, doi:10.5194/acp-6-947-2006, 2006.

Quaas, J., Ming, Y., Menon, S., Takemura, T., Wang, M., Penner, J. E., Gettelman, A., Lohmann, U., Bellouin, N., Boucher, O., Sayer, A. M., Thomas, G. E., McComiskey, A., Feingold, G., Hoose, C., Kristjánsson, J. E., Liu, X., Balkanski, Y., Donner, L. J., Ginoux, P. A., Stier, P., Grandey, B., Feichter, J., Sednev, I., Bauer, S. E., Koch, D., Grainger, R. G., Kirkevåg, A., Iversen, T., Seland, Ø., Easter, R., Ghan, S. J., Rasch, P. J., Morrison, H., Lamarque, J.-F., Iacono, M. J., Kinne, S., and Schulz, M.: Aerosol indirect effects - general circulation model intercomparison and evaluation with satellite data, Atmos. Chem. Phys., 9, 8697-8717, doi:10.5194/acp-9-8697-2009, 2009.

Quaas, J., Stevens, B., Stier, P., and Lohmann, U.: Interpreting the cloud cover - aerosol optical depth relationship found in satellite data using a general circulation model, Atmos. Chem. Phys., 10, 6129-6135, doi:10.5194/acp-10-6129-2010, 2010.

Randall, D., Khairoutdinov, M., Arakawa, A., and Grabowski, W.: Breaking the cloud parameterization deadlock, Bull. Amer. Meteor. Soc., 84, 1547, doi:10.1175/Bams-84-11-1547, 2003.

Rosenfeld, D., Kaufman, Y. J., and Koren, I.: Switching cloud cover and dynamical regimes from open to closed Benard cells in response to the suppression of precipitation by aerosols, Atmos. Chem. Phys., 6, 2503-2511, doi:10.5194/acp-6-2503-2006, 2006.

Rossow, W. B. and Schiffer, R. A.: Advances in understanding clouds from ISCCP, Bull. Amer. Meteor. Soc., 80, 2261-2287, 1999.

Rotstayn, L. D.: On the "tuning" of autoconversion parameterizations in climate models, J. Geophys. Res., 105, 15495-15507, 2000.

Savoie, D. I., Prospero, J. M., Larsen, R. J., Huang, F., Izaguirre, M. A., Huang, T., Snowdon, T. H., Custals, L., and Sanderson, C. G.: Nitrogen and Sulfur Species in Antarctic Aerosols at Mawson, Palmer Station, and Marsh (King George Island), J. Atmos. Chem., 17, 95-122, 1993.

Savoie, D. L., Prospero, J. M., and Saltzman, E. S.: Nitrate, nonseasalt sulfate and methanesulfonate over the Pacific Ocean, in: Chemical Oceanography, edited by: Ridley, J. P., Chester, R., and Duce, R. A., Elsevier, New York, 219-250, 1989.

Small, J. D., Chuang, P. Y., Feingold, G., and Jiang, H. L.: Can aerosol decrease cloud lifetime?, Geophys. Res. Lett., 36, L16806, doi:10.1029/2009g1038888, 2009.

Stevens, B. and Feingold, G.: Untangling aerosol effects on clouds and precipitation in a buffered system, Nature, 461, 607-613, doi:10.1038/Nature08281, 2009.

Suzuki, K., Nakajima, T., Numaguti, A., Takemura, T., Kawamoto, K., and Higurashi, A.: A study of the aerosol effect on a cloud field with simultaneous use of GCM modeling and satellite observation, J. Atmos. Sci., 61, 179-194, 2004.

Suzuki, K., Nakajima, T., Satoh, M., Tomita, H., Takemura, T., Nakajima, T. Y., and Stephens, G. L.: Global cloud-systemresolving simulation of aerosol effect on warm clouds, Geophys. Res. Lett., 35, L19817, doi:10.1029/2008g1035449, 2008. 
Tao, W. K., Chern, J. D., Atlas, R., Randall, D., Khairoutdinov, M., Li, J. L., Waliser, D. E., Hou, A., Lin, X., Peters-Lidard, C., Lau, W., Jiang, J., and Simpson, J.: A Multiscale Modeling System Developments, Applications, and Critical Issues, Bull. Amer. Meteor. Soc., 90, 515, doi:10.1175/2008bams2542.1, 2009.

Tao, W. K., Simpson, J., Baker, D., Braun, S., Chou, M. D., Ferrier, B., Johnson, D., Khain, A., Lang, S., Lynn, B., Shie, C. L., Starr, D., Sui, C. H., Wang, Y., and Wetzel, P.: Microphysics, radiation and surface processes in the Goddard Cumulus Ensemble (GCE) model, Meteorol. Atmos. Phys., 82, 97-137, doi:10.1007/S00703-001-0594-7, 2003.

Thompson, G., Rasmussen, R. M., and Manning, K.: Explicit forecasts of winter precipitation using an improved bulk microphysics scheme. Part I: Description and sensitivity analysis, Mon. Wea. Rev., 132, 519-542, 2004.

Waliser, D. E., Li, J. L. F., Woods, C. P., Austin, R. T., Bacmeister, J., Chern, J., Del Genio, A., Jiang, J. H., Kuang, Z. M., Meng, H., Minnis, P., Platnick, S., Rossow, W. B., Stephens, G. L., SunMack, S., Tao, W. K., Tompkins, A. M., Vane, D. G., Walker, C., and $\mathrm{Wu}, \mathrm{D}$.: Cloud ice: A climate model challenge with signs and expectations of progress, J. Geophys. Res., 114, D00A21, doi:10.1029/2008JD010015, 2009.

Wang, M. and Penner, J. E.: Aerosol indirect forcing in a global model with particle nucleation, Atmos. Chem. Phys., 9, 239-260, doi:10.5194/acp-9-239-2009, 2009.

Wang, M. and Penner, J. E.: Cirrus clouds in a global climate model with a statistical cirrus cloud scheme, Atmos. Chem. Phys., 10, 5449-5474, doi:10.5194/Acp-10-5449-2010, 2010.

Wang, M., Ghan, S., Easter, R., Ovchinnikov, M., Liu, X., Kassianov, E., Qian, Y., Gustafson, W., Larson, V. E., Schanen, D. P., Khairoutdinov, M., and Morrison, H.: The multi-scale aerosolclimate model PNNL-MMF: model description and evaluation, Geosci. Model Dev., 4, 137-168, doi:10.5194/gmd-4-137-2011, 2011.
Weng, F. Z. and Grody, N. C.: Retrieval of cloud liquid water using the Special Sensor Microwave Imager (SSM/I), J. Geophys. Res., 99, 25535-25551, 1994.

Wolff, E. W. and Cachier, H.: Concentrations and seasonal cycle of black carbon in aerosol at a coastal Antarctic station, J. Geophys. Res., 103, 11033-11041, 1998.

Wood, R., Bretherton, C. S., Leon, D., Clarke, A. D., Zuidema, P., Allen, G., and Coe, H.: An aircraft case study of the spatial transition from closed to open mesoscale cellular convection over the Southeast Pacific, Atmos. Chem. Phys., 11, 2341-2370, doi:10.5194/Acp-11-2341-2011, 2011.

Wylie, D., Jackson, D. L., Menzel, W. P., and Bates, J. J.: Trends in global cloud cover in two decades of HIRS observations, J. Climate, 18, 3021-3031, 2005.

Xue, H. W., Feingold, G., and Stevens, B.: Aerosol effects on clouds, precipitation, and the organization of shallow cumulus convection, J. Atmos. Sci., 65, 392-406, doi:10.1175/2007jas2428.1, 2008.

Yoshioka, M., Mahowald, N. M., Conley, A. J., Collins, W. D., Fillmore, D. W., Zender, C. S., and Coleman, D. B.: Impact of desert dust radiative forcing on Sahel precipitation: Relative importance of dust compared to sea surface temperature variations, vegetation changes, and greenhouse gas warming, J. Climate, 20, 1445-1467, doi:10.1175/Jcli4056.1, 2007.

Zender, C. S., Bian, H. S., and Newman, D.: Mineral Dust Entrainment and Deposition (DEAD) model: Description and 1990s dust climatology, J. Geophys. Res., 108, 4416, doi:10.1029/2002jd002775, 2003.

Zhang, J. H., Lohmann, U., and Stier, P.: A microphysical parameterization for convective clouds in the ECHAM5 climate model: Single-column model results evaluated at the Oklahoma Atmospheric Radiation Measurement Program site, J. Geophys. Res., 110, D15S07, doi:10.1029/2004jd005128, 2005. 